This document was prepared in conjunction with work accomplished under Contract No. DE-AC09-96SR18500 with the U. S. Department of Energy.

\title{
DISCLAIMER
}

This report was prepared as an account of work sponsored by an agency of the United States Government. Neither the United States Government nor any agency thereof, nor any of their employees, nor any of their contractors, subcontractors or their employees, makes any warranty, express or implied, or assumes any legal liability or responsibility for the accuracy, completeness, or any third party's use or the results of such use of any information, apparatus, product, or process disclosed, or represents that its use would not infringe privately owned rights. Reference herein to any specific commercial product, process, or service by trade name, trademark, manufacturer, or otherwise, does not necessarily constitute or imply its endorsement, recommendation, or favoring by the United States Government or any agency thereof or its contractors or subcontractors. The views and opinions of authors expressed herein do not necessarily state or reflect those of the United States Government or any agency thereof. 


\section{EVALUATION OF SRAT SAMPLING DATA IN SUPPORT OF A SIX SIGMA YELLOW BELT PROCESS IMPROVEMENT PROJECT}

Thomas B. Edwards

June 2005

Statistical Consulting Section

Savannah River National Laboratory

Aiken, SC 29808

Prepared for the U.S. Department of Energy Under Contract Number DEAC09-96SR18500

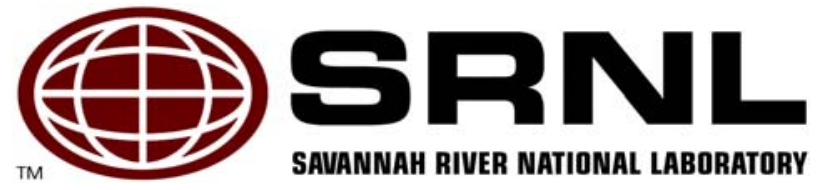




\section{DISCLAIMER}

This report was prepared by Westinghouse Savannah River Company (WSRC) for the United States Department of Energy under Contract No. DE-AC09-96SR18500 and is an account of work performed under that contract. Neither the United States Department of Energy, nor WSRC, nor any of their employees makes any warranty, expressed or implied, or assumes any legal liability or responsibility for the accuracy, completeness, or usefulness, of any information, apparatus, or product or process disclosed herein or represents that its use will not infringe privately owned rights. Reference herein to any specific commercial product, process, or service by trademark, name, manufacturer or otherwise does not necessarily constitute or imply endorsement, recommendation, or favoring of same by WSRC or by the United States Government or any agency thereof. The views and opinions of the authors expressed herein do not necessarily state or reflect those of the United States Government or any agency thereof.

\section{Printed in the United States of America \\ Prepared For \\ U.S. Department of Energy}

The Savannah River National Laboratory is operated for the U.S. Department of Energy by Westinghouse Savannah River Company. 
Key Words: statistics, uncertainty, error propagation, simulation, confidence level,

Retention: Permanent

\section{EVALUATION OF SRAT SAMPLING DATA IN SUPPORT OF A SIX SIGMA YELLOW BELT PROCESS IMPROVEMENT PROJECT}

Thomas B. Edwards

June 2005

Statistical Consulting Section

Savannah River National Laboratory

Aiken, SC 29808

Prepared for the U.S. Department of Energy Under Contract Number DEAC09-96SR18500

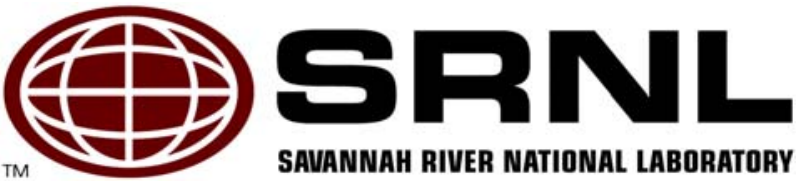




\section{REVIEWS AND APPROVALS}

\section{AUTHOR:}
Ohomas $B$
Gluarde
$7-7.05$
T. B. Edwards, Statistical Consulting Section
Date

\section{TECHNICAL REVIEWERS:}

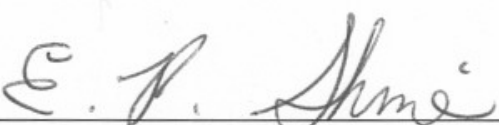

$$
\frac{7-7-05}{\text { Date }}
$$

E. P. Shine, Statistical Consulting Section

$$
7-7-05
$$

C. C. Herman, Immobilization Technology Section

Date

\section{APPROVERS:}

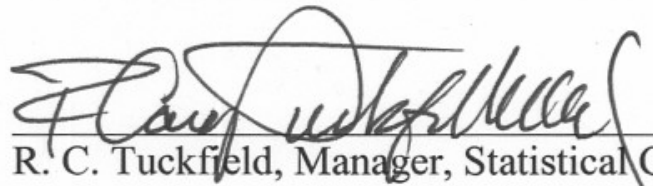

Shavon \& Mara

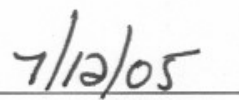

S. L. Marra, Manager, Immobilization Technology Section

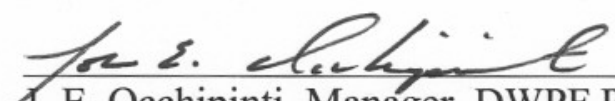

J. E. Occhipinti, Manager, DWPF Process Engineering

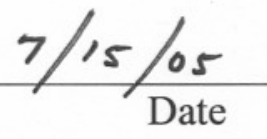




\section{EXECUTIVE SUMMARY}

As part of the Six Sigma continuous improvement initiatives at the Defense Waste Processing Facility (DWPF), a Yellow Belt team was formed to evaluate the frequency and types of samples required for the Sludge Receipt and Adjustment Tank (SRAT) receipt in the DWPF. The team asked, via a technical task request, that the Statistical Consulting Section (SCS), in concert with the Immobilization Technology Section (ITS) (both groups within the Savannah River National Laboratory (SRNL)), conduct a statistical review of recent SRAT receipt results to determine if there is enough consistency in these measurements to allow for less frequent sampling. As part of this review process, key decisions made by DWPF Process Engineering that are based upon the SRAT sample measurements are outlined in this report. For a reduction in SRAT sampling to be viable, these decisions must not be overly sensitive to the additional variation that will be introduced as a result of such a reduction.

Measurements from samples of SRAT receipt batches 314 through 323 were reviewed as part of this investigation into the frequency of SRAT sampling. The associated acid calculations for these batches were also studied as part of this effort.

The results from this investigation showed no indication of a statistically significant relationship between the tank solids and the acid additions for these batches. One would expect that as the tank solids increase there would be a corresponding increase in acid requirements. There was, however, an indication that the predicted reduction/oxidation (REDOX) ratio (the ratio of $\mathrm{Fe}^{2+}$ to the total $\mathrm{Fe}$ in the glass product) that was targeted by the acid calculations based on the SRAT receipt samples for these batches was on average 0.0253 larger than the predicted REDOX based upon Slurry Mix Evaporator (SME) measurements. This is a statistically significant difference (at the 5\% significance level), and the study also suggested that the difference was due to predictions of the formate and Mn concentrations in the SME product that were made at the time of the acid addition in the SRAT. For each of these analytes, the SRAT version was statistically different from the SME version (units are moles/kg SME product slurry): the SRAT values were, on average, 0.0914 larger than the SME values for formate and 0.0089 smaller than the SME values for Mn. A look at the signs of the terms corresponding to these two analytes in equation (2) indicates that both of these differences contribute to the calculated REDOX differences between the SRAT and SME product.

Based upon the results from this study, when targeting a stoichiometric factor of $155 \%$ using average measurements for the SRAT receipt, the actual factor realized for any given batch would be expected to fall within the interval from $133.3 \%$ to $176.7 \%$ with $95 \%$ confidence. When targeting a REDOX of $\sim 0.2$ using average measurements, the actual factor realized for any given batch would be expected to fall within the interval from 0.166 to 0.234 with $95 \%$ confidence.

Based on the results of this study, the following recommendations are made:

- DWPF should consider adjusting their acid calculation to align the Mn concentration in SRAT receipt with the Mn concentration in the SME product.

- DWPF should consider adjusting their acid addition strategy to introduce a 9.7\% loss (as a 0.903 correction factor) as part of the evaluation of formate in the SME product portion of their spreadsheet.

- DWPF should evaluate how a $\pm 14 \%$ uncertainty in their targeted stoichiometric factor and a $\pm 17 \%$ uncertainty in the targeted REDOX may affect the success of their acid addition strategy. 
WSRC-TR-2005-00292

Revision 0

This page intentionally left blank. 


\section{TABLE OF CONTENTS}

EXECUTIVE SUMMARY iii

LIST OF TABLES vi

LIST OF Figures vi

LIST OF ACRONYMS vi

1.0 INTRODUCTION AND BACKGROUND 1

2.0 RESULTS 1

2.1 DWPF's Acid Addition Strategy 2

2.2 SRAT Receipt Measurements for Batches 314 through 323

2.3 REDOX Predictions at SRAT Receipt versus REDOX Predictions at the SME 6

2.4 Variation in Acid Addition Amounts and REDOX Predictions 8

2.4.1 Error Propagation of Process Variations 8

2.4.2 A Simulation of the Sensitivity of the Acid Calculation to Process Variation 9

2.4.3 Reenactment of the Acid Calculation for Batches 314 through $323 \quad 10$

2.4.4 Summarizing the Results 11

3.0 CONCLUSIONS 12

4.0 RECOMMENDATIONS 13

5.0 REFERENCES 13

6.0 ACKNOWLEDGEMENTS 14

APPENDIX Supporting Tables and Exhibits 15 


\section{LIST OF TABLES}

Table 2-1 Correlations between Average Measurements by Batch...................................... 5

Table 2-2 Tank Volume, Nitric Acid Addition, and Formic Acid Addition by Batch............ 5

Table 2-3 Comparisons of Melter Feed Predictions at the SRAT to SME Measurements...... 6

Table 2-4 Descriptive Statistics for the Measurements from SRAT Receipt Batches 314

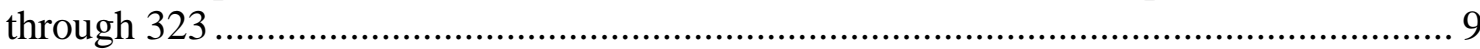

Table 2-5 Outcome from Reenactment of Acid Additions for SRAT Receipt Batches 314 through 323 10

Table 2-6 Descriptive Statistics for the Measurements from SRAT Receipt Batches 314

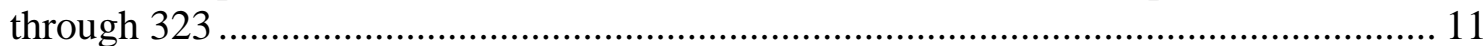

\section{LIST OF FIGURES}

Figure 2-1 Overview of Critical Steps in the DWPF Process that Influence Inputs to REDOX

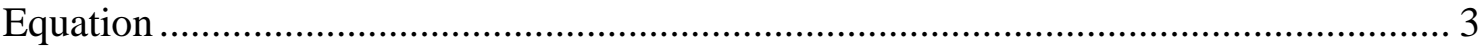

Figure 2-2 Scatterplot Matrix of the Average Measurements by Batch ............................... 4

Figure 2-3 Acid Additions versus SRAT Receipt Total Sludge Solids .............................. 6

Figure 2-4 Paired Comparisons of SME Measurements versus SRAT Predictions ................ 7

Figure 2-5 Descriptive Statistics of Actual Stoichiometric Factors versus the Anticipated

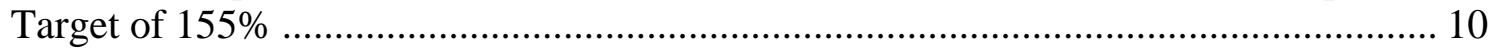

Figure 2-6 Descriptive Statistics of REDOX Differences .............................................. 11

\section{LIST OF ACRONYMS}

DWPF Defense Waste Processing Facility

HLW High Level Waste

ITS Immobilization Technology Section

JMP Pronounced “jump.” It's a statistical software package, a registered trademark of SAS Institute, Inc.

SCS Statistical Consulting Section

SME Slurry Mix Evaporator

SRAT Sludge Receipt and Adjustment Tank

SRNL Savannah River National Laboratory

SRS Savannah River Site 


\subsection{INTRODUCTION AND BACKGROUND}

The Defense Waste Processing Facility (DWPF) Analytical Laboratory routinely conducts chemical analyses of tank samples at several points during the processing of High Level Waste (HLW) at the DWPF. Included in the samples submitted to the laboratory for such analyses are samples of the Sludge Receipt and Adjustment Tank (SRAT) after the receipt of each process batch (designated as SRAT receipt samples) and just prior to the transfer of the SRAT material to the Slurry Mix Evaporator (SME) (designated as SRAT product samples). Currently, the time required to take, analyze, report, and interpret the results from these SRAT samples does not delay the processing in DWPF, but in the future, with the incorporation of possible salt streams into the feed going to DWPF and with other facility improvements, it could. In addition, analyzing the samples requires the time of both laboratory personnel and equipment and interpreting the sample results requires the time of process engineers. All of these resources are in limited supply, and there is a need to leverage their use for maximum impact on the DWPF operation. Finally, the processing of samples in the laboratory generates waste with a corresponding disposal cost. Reducing the number of samples processed reduces the waste and, thus, reduces these disposal costs.

As part of the Six Sigma continuous improvement initiatives at the DWPF, a Yellow Belt team was formed to evaluate the frequency and types of samples required for the SRAT receipt and SRAT product in the DWPF. The team asked, via a technical task request (TTR) [1], that the Statistical Consulting Section (SCS), in concert with the Immobilization Technology Section (ITS) (both groups within the Savannah River National Laboratory (SRNL)), conduct a statistical review of recent SRAT receipt results to determine if there is enough consistency in these measurements to allow for less frequent sampling or for fewer analyses per sample. As part of this review process, the decisions made by DWPF Process Engineering that are based upon the SRAT sample measurements and other process information are outlined in this report. For a reduction in SRAT sampling to be viable, these decisions must not be overly sensitive to the additional variation that will be introduced as a result of such a reduction.

The purpose of this report, as directed by the task technical and quality assurance plan [2], is to quantify the additional variation that would be expected if there were a reduction in the SRAT sampling frequency, to propagate this variation through the calculations conducted by Process Engineering, and to offer a recommended path forward for SRAT receipt sampling and for the Engineering calculations that rely on the information generated from the SRAT receipt samples.

\subsection{RESULTS}

The SRAT receipt measurements are used by DWPF's Process Engineering group to perform the acid calculation for the SRAT batch. This calculation utilizes predictive models: one equation predicts the total acid requirements for the batch and the other equation predicts the reduction/oxidation (REDOX) state of the glass product that will be produced by processing the batch. The inputs to these equations are either directly or indirectly related to measurements derived from the SRAT receipt samples.

If the SRAT receipt is sampled less frequently than every batch, then a set of average measurements would be used to drive the predictions from these two equations for the un-sampled batches. How much might the predictions generated from using these averages differ from the predictions that would have been generated from using measurements from samples of the individual SRAT receipt batch? This question is tackled in the sections below.

To start off, the two predictive equations are discussed. Secondly, SRAT receipt measurement data for samples from batches 313 through 323 are presented and a statistical analysis of these measurements is 
provided. Then, comparisons are presented between the REDOX predictions made using the SRAT receipt and those made using Slurry Mix Evaporator (SME) measurements. Finally, different approaches are used to evaluate the impact of less frequent sampling on the acid addition process. The statistical analyses presented as part of these discussions were carried out using JMP® Version 5.1.2 [3] from SAS Institute, Inc.

\subsection{DWPF's Acid Addition Strategy}

On its simplest level, DWPF's acid addition strategy consists of two decisions: (1) How much total acid (the total number of moles) should be added to the SRAT batch? and (2) What is the relative proportion of formic to nitric acid that should be used to appropriately target REDOX in meeting the total acid requirement? To answer the first question, DWPF utilizes an equation that was presented in [4] that relates the total acid requirement for a SRAT batch to key characteristics and measurements of the SRAT receipt. The relationship is given by equation (1):

$$
\mathrm{A}_{\mathrm{T}}=\text { moles acid }=\mathrm{V}_{\mathrm{S}} *\left[1.0 * \text { B.E. }+\rho_{\mathrm{S}} *\left(\frac{0.75 * \mathrm{NO}_{2}^{-}}{46.007}+\frac{\mathrm{Hg}}{200.6}+\frac{2.0 * \mathrm{TIC}}{12.01}+\frac{1.2 * \mathrm{Mn}}{54.938}\right)\right] * \text { factor }
$$

where

$\mathrm{A}_{\mathrm{T}} \quad$ is the total acid requirement in moles,

$\mathrm{V}_{\mathrm{S}} \quad$ is the SRAT receipt slurry volume, $\mathrm{L}$,

$\rho_{\mathrm{S}} \quad$ is the SRAT receipt slurry density, $\mathrm{kg} / \mathrm{L}$,

B.E. is the SRAT receipt base equivalents at $\mathrm{pH}$ 7, equivalent moles $\mathrm{OH}-/ \mathrm{L}$,

$\mathrm{NO}_{2}{ }^{-}$is the SRAT receipt mass of nitrite ion per unit mass slurry,

TIC is the SRAT receipt mass to total inorganic carbon (TIC) per unit mass slurry,

$\mathrm{Hg}$ is the SRAT receipt mass of mercury per unit mass slurry,

$\mathrm{Mn} \quad$ is the SRAT receipt mass of manganese per unit mass slurry, and

factor is a multiplier (called the stoichiometric value or factor) to increase the total acid above that predicted by the four terms.

In addition to adjusting the rheology of the SRAT material, the added acid must satisfy two goals during SRAT processing: the amount of nitrite in the SRAT material must be destroyed to below the level of concern and the amount of hydrogen generated during subsequent processing must be below the DWPF safety basis limit. The minimum acid, required to destroy the nitrite, and the maximum acid, that can be added before the generation of hydrogen at problem levels, define the "operating window" for the acid addition strategy. The operating window may be represented using an interval of values for the stoichiometric factor of equation (1). For batches 314 through 323 (the focus of this study), the stoichiometric factors were near 1.55 or $155 \%$.

The answer to the second question above is determined using an equation from [5] that predicts the REDOX of DWPF's glass product. In this case, REDOX is represented as the ratio of $\mathrm{Fe}^{2+}$ to the total iron in the glass. The REDOX equation relates this ratio to the electron equivalents, $\xi$, for critical components of the slurry product that is fed to DWPF's melter. The overall relationship between the REDOX ratio and $\xi$ may be expressed as in equation (2):

$$
\frac{\mathrm{Fe}^{2+}}{\Sigma \mathrm{Fe}}=\mathrm{f}\left[\left(2[\mathrm{~F}]+4[\mathrm{C}]+4\left[\mathrm{O}_{\mathrm{T}}\right]-5[\mathrm{~N}]-2[\mathrm{Mn}]\right) \frac{45}{\mathrm{~T}}\right]=\mathrm{f}[\xi]
$$


where

$$
\begin{array}{lll}
\mathrm{f} & = & \text { indicates a function } \\
{[\mathrm{F}]} & = & \text { formate }(\mathrm{mol} / \mathrm{kg} \text { feed }) \\
{[\mathrm{C}]} & = & \text { coal }(\text { carbon) }(\mathrm{mol} / \mathrm{kg} \text { feed }) \\
{\left[\mathrm{O}_{\mathrm{T}}\right]=} & \text { oxalate } \\
{[\mathrm{N}]} & = & \text { nitrate }+ \text { nitrite }(\mathrm{mol} / \mathrm{kg} \text { feed }) \\
{[\mathrm{Mn}]=} & \text { manganese }(\mathrm{mol} / \mathrm{kg} \text { feed }) \\
\mathrm{T} & = & \text { total solids }(\mathrm{wt} \%) \\
\text { and } \xi \text { (mol/kg feed at } 45 \mathrm{wt} \% \text { solids) }=\left(2[\mathrm{~F}]+4[\mathrm{C}]+4\left[\mathrm{O}_{\mathrm{T}}\right]-5[\mathrm{~N}]-2[\mathrm{Mn}]\right) \frac{45}{\mathrm{~T}}
\end{array}
$$

The final form of the REDOX equation from [5] may be expressed as equation (3):

$$
\frac{\mathrm{Fe}^{2+}}{\Sigma \mathrm{Fe}}=0.1942+0.1910 \xi
$$

For REDOX, the operating window is the interval of values from 0.01 to 0.33 [5]. Typically, DWPF targets a value near 0.2 for REDOX. This was the case for batches 314 through 323.

Before leaving this section, one additional aspect of the REDOX equation should be explored. Note that the inputs to equation (2) are expressed in terms of melter feed, which may be thought of equivalently as the SME product. Figure 2-1 provides an overview of critical steps in the DWPF processing that occur from acid addition at the SRAT to the formation of the SME product.

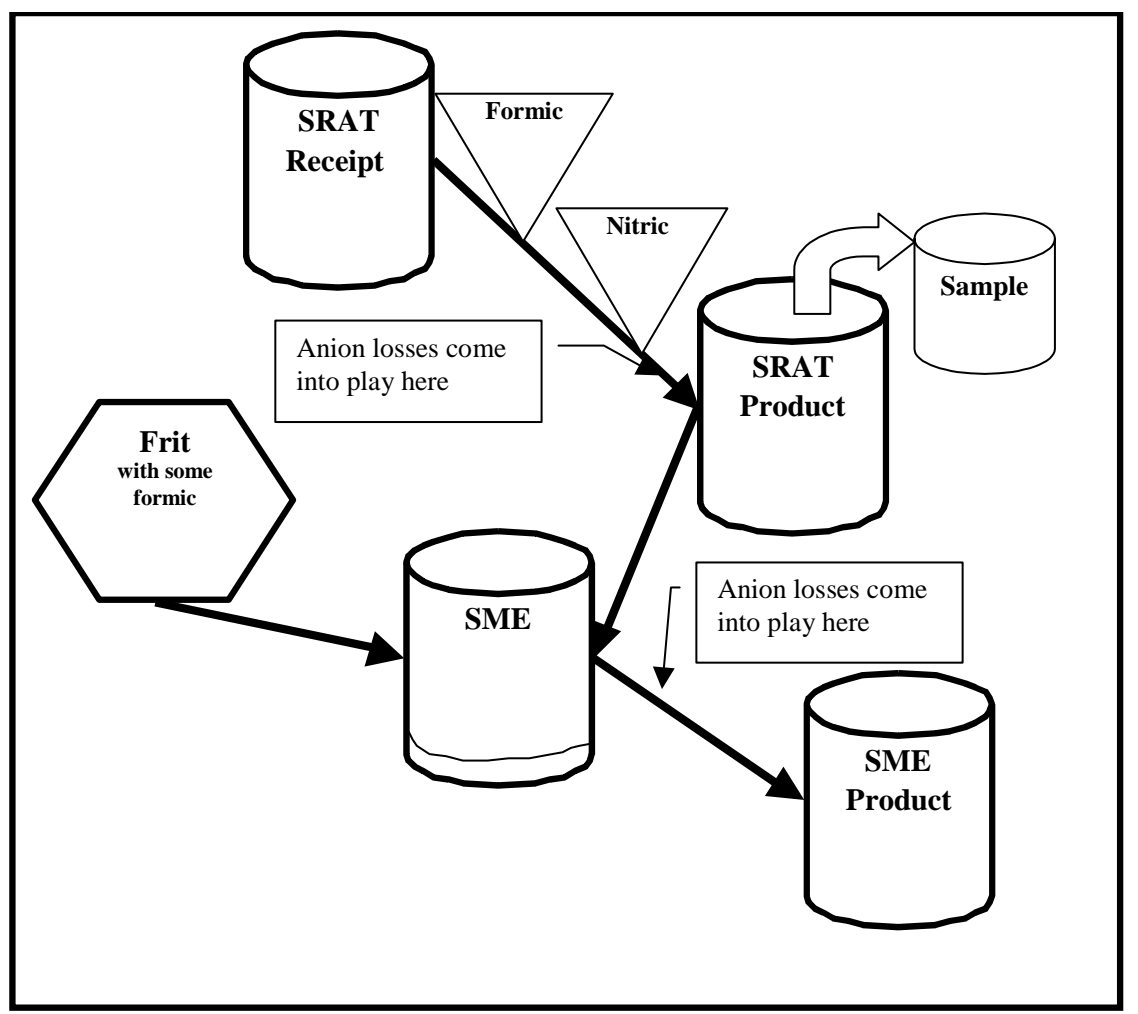

Figure 2-1 Overview of Critical Steps in the DWPF Process that Influence Inputs to REDOX Equation 
Since the acid calculation for a process batch is conducted at the SRAT receipt step (as indicated in the figure), there are three categories of information used to estimate the REDOX of the SME product that will be produced for this batch: the SRAT receipt measurements, the nitric and formic acid additions, and some insight, through assumptions and process experience, of what happens to the SRAT receipt material as it makes it way through to the melter. A closer look at these assumptions and at the use of process experience to aid these calculations is presented later in this report.

\subsection{SRAT Receipt Measurements for Batches 314 through 323}

Table A1 in the Appendix provides a listing of the measurements of the SRAT receipt for batches 314 through 323 that were used as inputs for the acid calculation for these batches. Exhibit A1 in the Appendix provides plots of these data by batch number. The values are reasonably stable although some trending may be indicated for some of the analytes over these data. Figure 2-2 provides a scatterplot matrix of the average values over the batches for these measurements. This plot reveals some strong correlations among certain pairs of measurements. This is also reflected in Table 2-1, which provides the pairwise linear correlations for these data. Some of these correlations are at or above 0.90 .

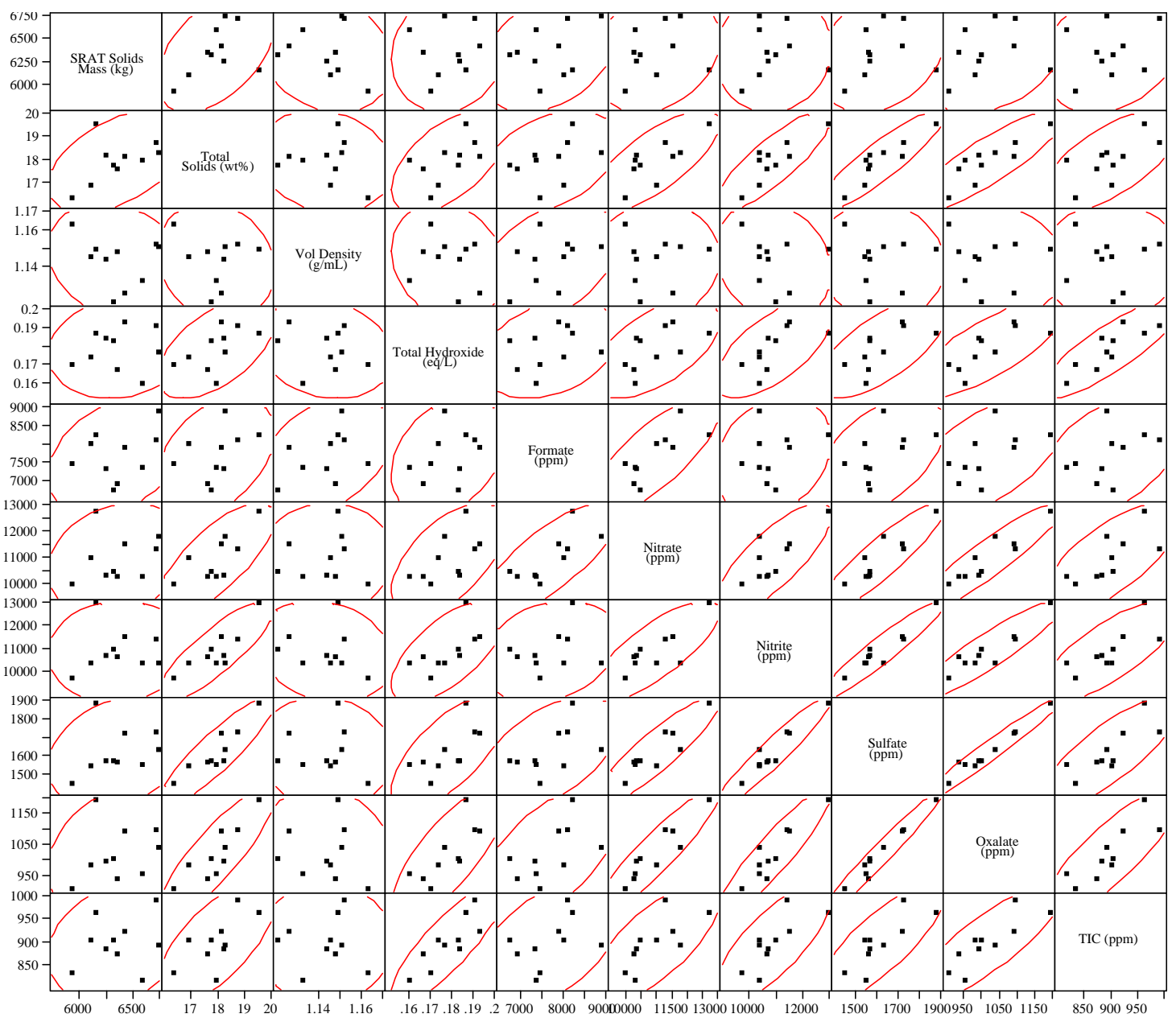

Figure 2-2 Scatterplot Matrix of the Average Measurements by Batch 
Table 2-1 Correlations between Average Measurements by Batch

\begin{tabular}{|c|c|c|c|c|c|c|c|c|c|c|}
\hline & $\begin{array}{c}\text { SRAT } \\
\text { Solids } \\
\text { Mass (kg) } \\
\end{array}$ & $\begin{array}{l}\text { Total } \\
\text { Solids } \\
\text { (wt\%) }\end{array}$ & $\begin{array}{c}\text { Vol } \\
\text { Density } \\
\text { (g/mL) }\end{array}$ & $\begin{array}{c}\text { Total } \\
\text { Hydroxide } \\
\text { (eq/L) } \\
\end{array}$ & $\begin{array}{c}\text { Formate } \\
\text { (ppm) }\end{array}$ & $\begin{array}{l}\text { Nitrate } \\
\text { (ppm) }\end{array}$ & $\begin{array}{l}\text { Nitrite } \\
\text { (ppm) }\end{array}$ & $\begin{array}{c}\text { Sulfate } \\
\text { (ppm) }\end{array}$ & $\begin{array}{l}\text { Oxalate } \\
\text { (ppm) }\end{array}$ & $\begin{array}{c}\text { TIC } \\
\text { (ppm) }\end{array}$ \\
\hline $\begin{array}{c}\text { SRAT } \\
\text { Solids } \\
\text { Mass (kg) }\end{array}$ & 1.0000 & 0.4827 & -0.2210 & 0.1120 & 0.3514 & 0.2217 & 0.0647 & 0.2701 & 0.2386 & 0.2309 \\
\hline $\begin{array}{l}\text { Total } \\
\text { Solids } \\
\text { (wt\%) }\end{array}$ & 0.4827 & 1.0000 & -0.1543 & 0.5594 & 0.3835 & 0.7376 & 0.8462 & 0.8969 & 0.8613 & 0.6663 \\
\hline $\begin{array}{c}\text { Vol } \\
\text { Density } \\
\text { (g/mL) }\end{array}$ & -0.2210 & -0.1543 & 1.0000 & -0.1807 & 0.3822 & 0.0549 & -0.1931 & -0.0758 & -0.0968 & 0.0174 \\
\hline $\begin{array}{c}\text { Total } \\
\text { Hydroxide } \\
(\mathrm{eq} / \mathrm{L})\end{array}$ & 0.1120 & 0.5594 & -0.1807 & 1.0000 & 0.3201 & 0.5773 & 0.6568 & 0.6788 & 0.7684 & 0.8409 \\
\hline $\begin{array}{c}\text { Formate } \\
(\mathrm{ppm})\end{array}$ & 0.3514 & 0.3835 & 0.3822 & 0.3201 & 1.0000 & 0.7674 & 0.2482 & 0.5092 & 0.5710 & 0.4354 \\
\hline $\begin{array}{l}\text { Nitrate } \\
(\mathrm{ppm})\end{array}$ & 0.2217 & 0.7376 & 0.0549 & 0.5773 & 0.7674 & 1.0000 & 0.7856 & 0.9017 & 0.9237 & 0.7200 \\
\hline $\begin{array}{l}\text { Nitrite } \\
\text { (ppm) }\end{array}$ & 0.0647 & 0.8462 & -0.1931 & 0.6568 & 0.2482 & 0.7856 & 1.0000 & 0.9484 & 0.9190 & 0.7625 \\
\hline $\begin{array}{c}\text { Sulfate } \\
(\mathrm{ppm})\end{array}$ & 0.2701 & 0.8969 & -0.0758 & 0.6788 & 0.5092 & 0.9017 & 0.9484 & 1.0000 & 0.9775 & 0.8047 \\
\hline $\begin{array}{l}\text { Oxalate } \\
\text { (ppm) }\end{array}$ & 0.2386 & 0.8613 & -0.0968 & 0.7684 & 0.5710 & 0.9237 & 0.9190 & 0.9775 & 1.0000 & 0.8424 \\
\hline $\begin{array}{c}\text { TIC } \\
(\mathrm{ppm})\end{array}$ & 0.2309 & 0.6663 & 0.0174 & 0.8409 & 0.4354 & 0.7200 & 0.7625 & 0.8047 & 0.8424 & 1.0000 \\
\hline
\end{tabular}

The sample measurements were used to develop an estimated volume (in gallons) for each SRAT batch by DWPF Engineering. The estimated tank volumes and the acid addition volumes determined by DWPF Engineering for these batches are presented in Table 2-2. Not listed, but of importance for both the total acid and REDOX equations, is the concentration of $\mathrm{Mn}$ (3.67 $\mathrm{wt} \%$ on a dried solids basis) that is used for each of these batches. Exhibit A2 in the Appendix provides plots of these data by batch number.

Table 2-2 Tank Volume, Nitric Acid Addition, and Formic Acid Addition by Batch

\begin{tabular}{|c|c|c|c||}
\hline Batch & $\begin{array}{c}\text { Volume } \\
\text { (gal) }\end{array}$ & $\begin{array}{c}\text { Nitric } \\
\text { (gal) }\end{array}$ & $\begin{array}{c}\text { Formic } \\
\text { (gal) }\end{array}$ \\
\hline 314 & 8375 & 95 & 350 \\
\hline 315 & 7345 & 85 & 345 \\
\hline 316 & 8325 & 90 & 365 \\
\hline 317 & 8225 & 95 & 365 \\
\hline 318 & 8475 & 80 & 340 \\
\hline 319 & 7950 & 90 & 335 \\
\hline 320 & 8385 & 85 & 345 \\
\hline 321 & 8225 & 80 & 325 \\
\hline 322 & 8525 & 80 & 325 \\
\hline 323 & 8350 & 85 & 350 \\
\hline
\end{tabular}

Figure 2-3 provides the results of fitting the values for nitric acid, formic acid, and total acid (in gallons) to the total solids of the SRAT receipt to see if any of these critical acid addition amounts appeared to be closely tied to this measure of the SRAT receipt. Each plot shows the average value (as a horizontal line) 
for the measurements on the y-axis along with a trend line and its $95 \%$ confidence interval. None of the trends lines are statistically significant at the $5 \%$ significance level. Thus, there is no indication of a statistically significant relationship between the tank sludge solids and the acid addition volumes. One would have expected that as the tank solids increase there would be a corresponding increase in the acid requirements.

Bivariate Fit

Nitric (gal) By Total Solids (kg)

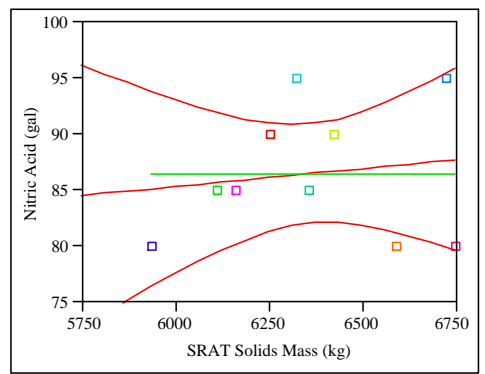

Bivariate Fit

Formic (gal) By Total Solids (kg)

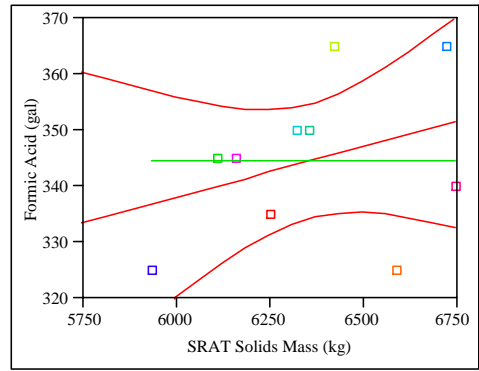

Bivariate Fit

Total acid(gal) By Total Solids (kg)

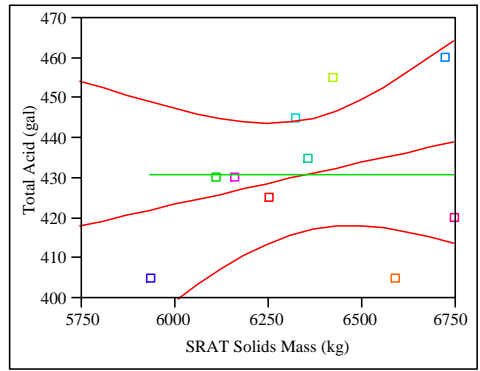

Figure 2-3 Acid Additions versus SRAT Receipt Total Sludge Solids

\subsection{REDOX Predictions at SRAT Receipt versus REDOX Predictions at the SME}

Comparisons between the predictions of the SME product at the time of the acid additions in the SRAT ${ }^{1}$ and the measurements of the SME product taken much later in the process were another area of interest in this study. Table 2-3 provides the data for these comparisons, and the comparisons are provided in Figure 2-4.

Table 2-3 Comparisons of Melter Feed Predictions at the SRAT to SME Measurements

\begin{tabular}{|c|c|c|c|c|c|c|c|c||}
\hline \hline Batch & $\begin{array}{c}\text { REDOX } \\
\text { Prediction } \\
\text { (SRAT) }\end{array}$ & $\begin{array}{c}\text { REDOX } \\
\text { Prediction } \\
\text { (SME) }\end{array}$ & $\begin{array}{c}\text { SME } \\
\text { Formate } \\
\text { (Predicted } \\
\text { at SRAT) }\end{array}$ & $\begin{array}{c}\text { Actual } \\
\text { SME } \\
\text { Formate }\end{array}$ & $\begin{array}{c}\text { SME } \\
\text { NO } \text { NO }_{2} \\
\text { (Predicted } \\
\text { at SRAT) }\end{array}$ & $\begin{array}{c}\text { Actual } \\
\text { SME } \\
\text { NO }_{3} / \text { NO }_{2}\end{array}$ & $\begin{array}{c}\text { SME Mn } \\
\text { (Predicted } \\
\text { at SRAT) }\end{array}$ & $\begin{array}{c}\text { Actual } \\
\text { SME } \\
\text { Mn }\end{array}$ \\
\hline 314 & 0.185 & 0.167 & 0.988 & 0.886 & 0.362 & 0.341 & 0.128 & 0.137 \\
\hline 315 & 0.184 & 0.162 & 0.948 & 0.906 & 0.347 & 0.355 & 0.126 & 0.137 \\
\hline 316 & 0.185 & 0.169 & 0.981 & 0.939 & 0.36 & 0.361 & 0.128 & 0.139 \\
\hline 317 & 0.186 & 0.144 & 0.977 & 0.928 & 0.356 & 0.38 & 0.13 & 0.155 \\
\hline 318 & 0.175 & 0.135 & 0.943 & 0.807 & 0.354 & 0.341 & 0.133 & 0.149 \\
\hline 319 & 0.172 & 0.163 & 0.871 & 0.815 & 0.329 & 0.323 & 0.126 & 0.116 \\
\hline 320 & 0.168 & 0.148 & 0.922 & 0.847 & 0.355 & 0.347 & 0.124 & 0.136 \\
\hline 321 & 0.176 & 0.144 & 0.888 & 0.844 & 0.307 & 0.354 & 0.115 & 0.132 \\
\hline 322 & 0.167 & 0.135 & 0.938 & 0.734 & 0.331 & 0.315 & 0.134 & 0.129 \\
\hline 323 & 0.167 & 0.145 & 0.988 & 0.824 & 0.348 & 0.343 & 0.132 & 0.135 \\
\hline
\end{tabular}

1 Please note that this wording may be somewhat misleading. The REDOX predictions described as being at the time of the acid additions in the SRAT are actually the REDOX predictions based upon the SRAT product, after accounting for the formate and nitrate losses during SRAT processing. The REDOX predictions at the time of the acid additions in the SRAT were not available for batches 314 through 323. 
REDOX Prediction (SME) By REDOX Prediction (SRAT)

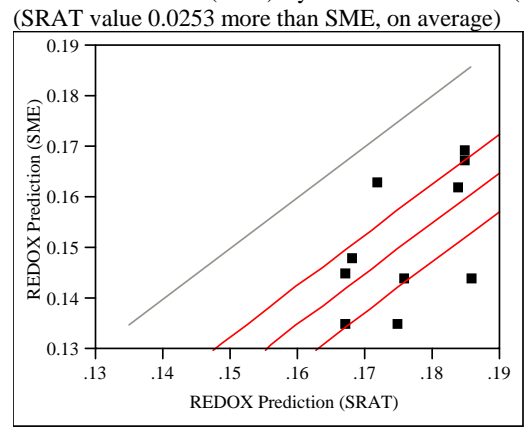

SME Formate By SME Formate (Predicted at SRAT) (SRAT value 0.0914 more than SME, on average)

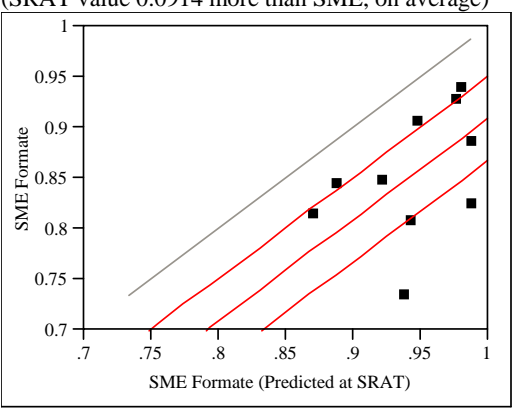

SME NO3/NO2 By SME NO3/NO2 (Predicted at SRAT) (SRAT value is only 0.0011 more than SME, on average)

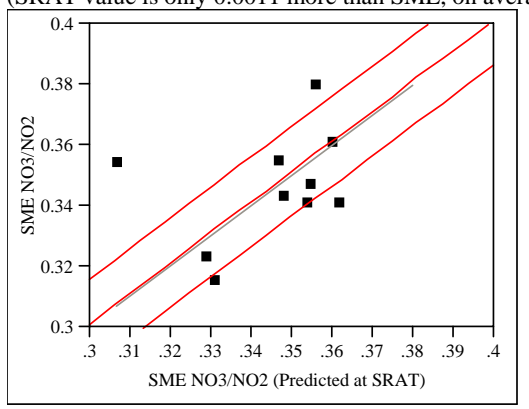

SME Mn By SME Mn (Predicted at SRAT) (SRAT value 0.0089 less than SME, on average)

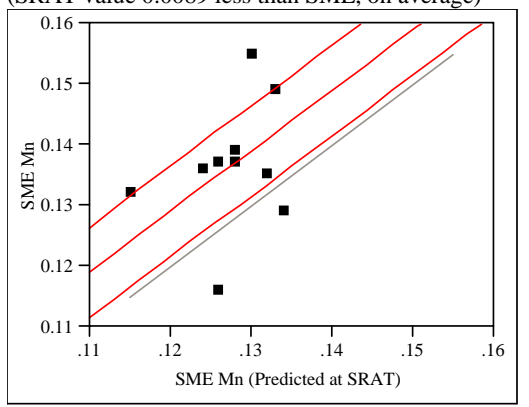

Figure 2-4 Paired Comparisons of SME Measurements versus SRAT Predictions

Figure 2-4 shows (in the upper left plot) that the predicted REDOX that is targeted for the acid calculations at the SRAT receipt is on average 0.0253 more than the predicted REDOX assessed based upon SME measurements. This is a statistically significant difference, and the other plots of Figure 2-4 suggest that it is due to the formate and Mn concentrations that are predicted for the SME product during the SRAT acid calculations. For each of these analytes, the SRAT prediction for the SME is statistically different (at the 5\% significance level) from the SME measurement (the units are moles $/ \mathrm{kg}$ of SME product slurry): the SRAT values are, on average, 0.0914 larger than the SME values for formate and 0.0089 smaller than the SME values for Mn. A look at the signs of the terms corresponding to these two analytes in equation (2) indicates that both of these differences between their SME and SRAT versions contribute to the REDOX differences between the SRAT and SME.

How might DWPF use the results from this section to make improvements in their acid addition strategy? Since the Mn concentration in the SRAT receipt is actually already an average value that is being used by DWPF, the results presented here suggest that the value currently being used in the SRAT (in the units of moles/kg of SME product slurry) is 0.0089 too small. On a percentage basis, since the SRAT Mn moles $/ \mathrm{kg}$ of SME product slurry averages (for batches 314 through 323) 0.1276 moles $/ \mathrm{kg}$, the value should be $100 \% \times(0.0089 / 0.1276)$ or $7 \%$ larger. Thus, instead of using $3.67 \mathrm{wt} \%$ as the value for the concentration of $\mathrm{Mn}$ on a dried solids basis, a value of 3.67×1.07=3.92 wt $\%$ might be used instead. As an alternative, there are assumptions regarding the weight percent dried solids for the SRAT product that may be affecting the Mn concentration predicted for the SME product. Adjustments to the acid calculations that eliminate the effect of these assumptions on the Mn concentration may be considered. Monitoring of the Mn assumed in the SRAT receipt versus the concentrations seen in the SME product should provide the data necessary to guide these decisions and to provide feedback as to their successful resolution. 
Another suggestion revolves around the evaluation of formate. Since DWPF is already adjusting for the formate and nitrate losses in the SRAT product from the SRAT receipt (as soon as these losses are realized), they are not the source of the formate discrepancy (of 0.0914 moles $/ \mathrm{kg}$ of SME product slurry) between the SRAT and SME. Based upon the fact that this discrepancy is about $100 \% \times(0.0914 / 0.9444)$ or $9.7 \%$ and that the SRAT versus SME nitrate/nitrite values do not indicate a similar problem, the most likely source of the discrepancy is believed to be a formate loss during SME processing. Thus, DWPF may want to consider adjusting their acid calculation to introduce a 9.7\% loss (as a 0.903 correction factor) as part of the evaluation of formate in the SME product portion of their acid calculation spreadsheet.

\subsection{Variation in Acid Addition Amounts and REDOX Predictions}

Assume that the acid calculation conducted by DWPF Engineering, which relies on the SRAT receipt measurements for each batch, yields the best estimates for the required amounts of formic and nitric for that batch. How much variation around these "best estimates" will be introduced if a set of average measurements is used for several SRAT batches instead of the individual measurements for each of these batches? That is, there is process variation from one batch to the next that the SRAT sample measurements capture and reflect that will be lost to the decision makers if they were to rely only on the average measurements from a set of previous SRAT receipt batches. The answer to this question is explored in this section.

Three different methods were used to help answer the question of the likely variation that may be introduced into the acid calculation by a less frequent sampling of the SRAT receipt. The first approach

was an error propagation of the process variation through the acid calculation. The second approach was a simulation of the impact of process variation on the acid calculation. Finally, the third approach is to reenact the acid calculations for batches 314 through 323 using the average of the measurements from these batches. Since there was a common goal for these approaches there should be a consistency in their outcomes.

\subsubsection{Error Propagation of Process Variations}

The propagation of errors through equations (1) and (2) was a reasonably straightforward process (see for example Appendix B of [6]); it was, however, more difficult for equation (2) than equation (1) due to the imbedded nature of the SRAT receipt measurements in that equation. The process variation was estimated based upon the data in Table A1. The averages and standard deviations of these measurements are provided in Table 2-4. For Mn and Hg, the values already remained relatively fixed (i.e., the SRAT receipt samples are not routinely analyzed for Mn nor for Hg, so the values don’t change often). 
Table 2-4 Descriptive Statistics for the Measurements from SRAT Receipt Batches 314 through 323

\begin{tabular}{||c|c|c|c||}
\hline Measurement & Average & $\begin{array}{c}\text { Standard } \\
\text { Deviation }\end{array}$ & $\begin{array}{c}\text { \% Relative } \\
\text { Standard } \\
\text { Deviation }\end{array}$ \\
\hline SRAT Solids Mass (kg) & 6361.8947 & 264.929 & 4.16 \\
\hline Total Solids (wt\%) & 17.9530 & 0.897 & 5.00 \\
\hline Density (g/mL) & 1.1433 & 0.013 & 1.12 \\
\hline Vol Density (g/mL) & 1.1432 & 0.013 & 1.13 \\
\hline Total Hydroxide (eq/L) & 0.1786 & 0.011 & 6.07 \\
\hline Formate (ppm) & 7697.5000 & 650.100 & 8.45 \\
\hline Nitrate (ppm) & 10964.5000 & 866.273 & 7.90 \\
\hline Nitrite (ppm) & 10918.2500 & 893.493 & 8.18 \\
\hline Sulfate (ppm) & 1620.7500 & 122.792 & 7.58 \\
\hline Oxalate (ppm) & 1020.2000 & 86.880 & 8.52 \\
\hline TIC (ppm) & 899.3075 & 52.861 & 5.88 \\
\hline SRAT Volume (gal) & 8218.0000 & 345.730 & 4.21 \\
\hline \hline
\end{tabular}

For equation (1), recall that the operating window for DWPF could be expressed as the target interval for the stoichiometric factor. The results from the error propagation suggest the following:

- that if the variations from batch to batch in the values of the critical inputs to equation (1) were uncorrelated the \% relative standard deviation in the stoichiometric factor would be $3.1 \%$.

- that if the variation from batch to batch in the values of the critical inputs to equation (1) were perfectly correlated the \% relative standard deviation in the stoichiometric factor would be $26.5 \%$.

For equation (2), the results from the error propagation suggest the following:

- that if the variations from batch to batch in the values of the critical inputs to equation (2) were uncorrelated the \%RSD in the REDOX prediction would be $7.0 \%$.

- that if the variation from batch to batch in the values of the critical inputs to equation (2) were perfectly correlated the \%RSD in the REDOX prediction would be $7.54 \%$.

\subsubsection{A Simulation of the Sensitivity of the Acid Calculation to Process Variation}

Expanding on the methodology developed in [7], a simulation of the acid calculation was conducted as part of this investigation. In the original simulation [7], the sensitivity of the acid addition strategy to measurement uncertainty was investigated whereas in this simulation, the sensitivity of the strategy to process variation was studied. Underlying this approach was an assumption that the process variations in the inputs to equations (1) and (2) were uncorrelated.

The results for equation (1) suggest that:

- if the variations from batch to batch in the values of the critical inputs to equation (1) were uncorrelated the \%RSD in the stoichiometric factor would be $3.8 \%$.

For equation (2), the results from the error propagation suggest that:

- if the variations from batch to batch in the values of the critical inputs to equation (2) were uncorrelated the \%RSD in the REDOX prediction would be $8.1 \%$. 


\subsubsection{Reenactment of the Acid Calculation for Batches 314 through 323}

DWPF Engineering used the average measurements in Table 2-4 as input for a second round of acid calculations for each of these batches. For each batch, a value of $155 \%$ was used as the targeted stoichiometric factor and a value for the total moles of required acid was determined based on the average measurements. The results are presented in Table 2-5, which provides these values as well as the value for the total moles of required acid based upon the receipt measurements for each SRAT batch. The actual targeted stoichiometric factor for each batch is also presented in this table.

Table 2-5 Outcome from Reenactment of Acid Additions for SRAT Receipt Batches 314 through 323

\begin{tabular}{|c|c|c|c|c||}
\hline $\begin{array}{c}\text { SRAT } \\
\text { Batch }\end{array}$ & $\begin{array}{c}\text { Targeted } \\
\text { Stoich. } \\
\text { Factor }\end{array}$ & $\begin{array}{c}\text { Total Moles of Acid } \\
\text { Required Based Upon } \\
\text { Averages }\end{array}$ & $\begin{array}{c}\text { Total Moles of Acid } \\
\text { Used Based Upon SRAT } \\
\text { Receipt Measurements }\end{array}$ & $\begin{array}{c}\text { Calculated Stoich. } \\
\text { Factor Based Upon } \\
\text { SRAT Measurements }\end{array}$ \\
\hline 314 & 155 & 34927.4 & 35057.3 & 154.43 \\
\hline 315 & 155 & 31048.9 & 34275.4 & 140.41 \\
\hline 316 & 155 & 34801.0 & 36259.0 & 148.77 \\
\hline 317 & 155 & 34822.0 & 37120.7 & 145.40 \\
\hline 318 & 155 & 35875.9 & 35442.9 & 156.89 \\
\hline 319 & 155 & 33494.0 & 33570.2 & 154.65 \\
\hline 320 & 155 & 35391.1 & 34234.7 & 160.24 \\
\hline 321 & 155 & 35011.7 & 32293.5 & 168.05 \\
\hline 322 & 155 & 35728.4 & 32291.9 & 171.50 \\
\hline 323 & 155 & 35285.7 & 34108.5 & 160.35 \\
\hline
\end{tabular}

The results from Table 2-5 suggest that when a set of average measurements was used to conduct the acid addition strategy for batches 314 through 323 at a targeted stoichiometry of $155 \%$, the actual stoichiometric factors that could have been realized ranged from $140.4 \%$ to $171.5 \%$. Figure $2-5$ provides a closer look at these values. The standard deviation of 9.63 translates into a \%RSD of $6.2 \%$. This value is between the estimated \%RSDs from the simulation and uncorrelated error propagation (3.8\% and $3.1 \%$, respectively) and the \%RSD from the correlated error propagation (26.5\%).

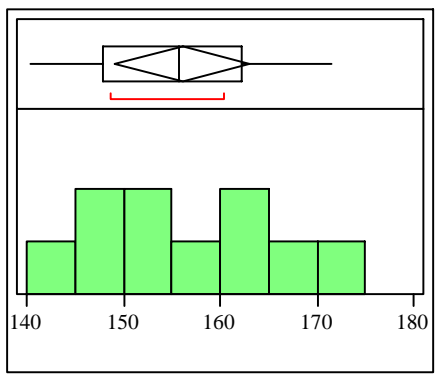

\begin{tabular}{lll}
\multicolumn{3}{c}{ Quantiles } \\
$100.0 \%$ & maximum & 171.50 \\
$99.5 \%$ & & 171.50 \\
$97.5 \%$ & & 171.50 \\
$90.0 \%$ & & 171.15 \\
$75.0 \%$ & quartile & 162.27 \\
$50.0 \%$ & median & 155.77 \\
$25.0 \%$ & quartile & 147.93 \\
$10.0 \%$ & & 140.91 \\
$2.5 \%$ & & 140.41 \\
$0.5 \%$ & & 140.41 \\
$0.0 \%$ & minimum & 140.41
\end{tabular}

\begin{tabular}{lr}
\multicolumn{2}{c}{ Moments } \\
Mean & 156.06725 \\
Std Dev & 9.631254 \\
Std Err Mean & 3.0456699 \\
upper 95\% Mean & 162.95704 \\
lower 95\% Mean & 149.17747 \\
$\mathrm{~N}$ & 10
\end{tabular}

Figure 2-5 Descriptive Statistics of Actual Stoichiometric Factors versus the Anticipated Target of 155\%

Table 2-6 provides the results of the impact on REDOX predictions of the reenactment of the acid addition strategy for batches 314 through 323. For each batch, as the acid calculation was reenacted the target for the predicted REDOX ratio was $\sim 0.2$. The actual targeted REDOX ratios ranged from 0.184 to 0.233 , as seen in Table 2-6. 
Table 2-6 Descriptive Statistics for the Measurements from SRAT Receipt Batches 314 through 323

\begin{tabular}{||c|c|c|c||}
\hline SRAT Batch & $\begin{array}{c}\text { REDOX targeted } \\
\text { using Averages }\end{array}$ & $\begin{array}{c}\text { Actual targeted REDOX } \\
\text { based upon SRAT } \\
\text { Measurements }\end{array}$ & $\begin{array}{c}\text { Difference in } \\
\text { REDOX Predictions }\end{array}$ \\
\hline 314 & 0.206 & 0.211 & -0.005 \\
\hline 315 & 0.206 & 0.184 & 0.022 \\
\hline 316 & 0.207 & 0.202 & 0.005 \\
\hline 317 & 0.207 & 0.202 & 0.005 \\
\hline 318 & 0.200 & 0.193 & 0.007 \\
\hline 319 & 0.197 & 0.201 & -0.004 \\
\hline 320 & 0.201 & 0.233 & -0.032 \\
\hline 321 & 0.197 & 0.213 & -0.016 \\
\hline 322 & 0.201 & 0.216 & -0.015 \\
\hline 323 & 0.198 & 0.205 & -0.007 \\
\hline
\end{tabular}

Figure 2-6 provides summary statistics of the differences in the REDOX targets. The standard deviation of the differences is 0.015 . When expressed as a percentage of the 0.2 target, the value is $7.5 \%$.
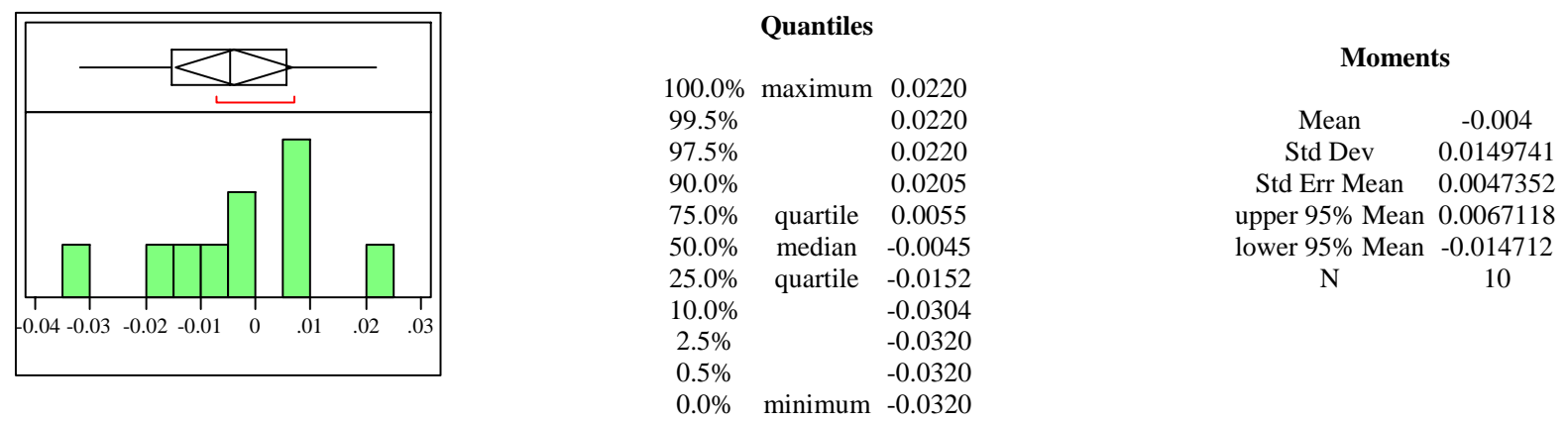

Figure 2-6 Descriptive Statistics of REDOX Differences

\subsubsection{Summarizing the Results}

Looking back over the three methods used to explore the impact of process variation on the acid addition strategy, there is a consistency in outcomes. For the total acid requirements, the \%RSDs for stoichiometric factors ranged from lows of 3.1\% (uncorrelated error propagation) and 3.0\% (uncorrelated simulation) to a high of 16.5 (correlated error propagation). The \%RSD for the reenactment was 6.2\%. This value falls within the interval of values seen for the other methods as would be expected and this value is believed to be the best estimate of the \%RSD. The value for the degrees of freedom for the \%RSD of $6.2 \%$ is the same as that for the degrees of freedom (9) of the standard deviations of the SRAT receipt measurements. Thus, the 95\% uncertainty for the stoichiometric factor is given by (see [6]):

$$
\text { Stoichiometric Factor Uncertainty@ } 95 \% \text { confidence }=\mathrm{t}_{0.025,9} \times(\% \mathrm{RSD})=2.262 \times 6.2 \%=14 \%
$$

where $t_{0.025}$, 9 is the upper 2.5\%-tail of the Student's $t$ distribution with 9 degrees of freedom. Thus, when targeting a stoichiometric factor of $155 \%$ using average measurements, the actual factor realized for any given batch would be expected to fall within the interval from $155 \times 0.86=133.3 \%$ to $155 \times 1.14=$ $176.7 \%$ with $95 \%$ confidence. 
The \%RSDs for REDOX from the three methods also show consistency. The \%RSDs range from a low of 7.0 for the uncorrelated error propagation to $8.1 \%$ for the uncorrelated simulation with a value of $7.54 \%$ for the correlated error propagation. The \%RSD for the reenactment was $7.5 \%$. This value falls within the interval of values for the other methods as would be expected and this value is believed to be the best estimate of the \%RSD. The value for the degrees of freedom for the \%RSD of $7.5 \%$ is the same as that for the degrees of freedom (9) of the standard deviations of the SRAT receipt measurements. Thus, the $95 \%$ uncertainty for the targeted REDOX is given by:

$$
\text { Targeted REDOX Uncertainty@ } 9_{5 \%} \text { confidence }=\mathrm{t}_{0.025,9} \times(\% \mathrm{RSD})=2.262 \times 7.5 \%=17 \%
$$

where, as above, $\mathrm{t}_{0.025}, 9$ is the upper 2.5\%-tail of the Student's $t$ distribution with 9 degrees of freedom. Thus, when targeting a REDOX of $\sim 0.2$ using average measurements, the actual value realized for any given batch would be expected to fall within the interval from $0.2 \times 0.83=0.166$ to $0.2 \times 1.17=0.234$ with $95 \%$ confidence.

From the perspective of stoichiometric factors and targeted REDOX values, it appears that the biggest challenge facing DWPF Engineering is the uncertainty of the stoichiometric factor. The question that must be addressed is whether or not both goals (nitrite destruction and hydrogen avoidance) associated with the acid addition strategy can be met at an adequate confidence level.

\subsection{CONCLUSIONS}

Measurements from samples of SRAT receipt batches 314 through 323 were reviewed as part of this investigation into the frequency of SRAT receipt sampling. The acid calculations for these batches were also studied as part of this effort.

The results from this investigation showed no indication of a statistically significant relationship between the tank solids and the acid additions for these batches. One would have expected that as the tank solids increase there would be a corresponding increase in the acid requirements. There was, however, an indication that the predicted REDOX values that were targeted by the acid calculations based on the SRAT receipt samples for these batches were on average 0.0253 larger than the predicted REDOX values assessed based upon SME product measurements. This was a statistically significant difference, and the study also suggested that the difference was due to predictions of SME product formate and Mn concentrations that were made in the SRAT acid calculation. For each of these analytes, the SRAT version was statistically different from the SME version (the units are moles/kg of SME product slurry): the SRAT values were, on average, 0.0914 larger than the SME values for formate and 0.0089 smaller than the SME values for Mn. A look at the signs of the terms corresponding to these two analytes in equation (2) indicates that both of these differences between their SME and SRAT versions contribute to the REDOX differences between the SRAT and SME.

Based upon the results of this study, when targeting a stoichiometric factor of $155 \%$ using average measurements, the actual factor realized for any given batch would be expected to fall within the interval from $133.3 \%$ to $176.7 \%$ with $95 \%$ confidence. When targeting a REDOX of $\sim 0.2$ using average measurements, the actual value realized for any given batch would be expected to fall within the interval from 0.166 to 0.234 with $95 \%$ confidence. 


\subsection{RECOMMENDATIONS}

Based on the results of this study, the following recommendations are made:

- DWPF should consider adjusting their acid calculation to align the Mn concentration in SRAT receipt with the Mn concentration in the SME product.

- DWPF should consider adjusting their acid calculation to introduce a 9.7\% loss (as a 0.903 correction factor) as part of the evaluation of formate in the SME product portion of their spreadsheet.

- DWPF should evaluate how a $\pm 14 \%$ uncertainty in their targeted stoichiometric factor and a $\pm 17 \%$ uncertainty in the REDOX prediction may affect the success of their operating strategy.

\subsection{REFERENCES}

[1] Patel, PM, “Technical Task Request: Evaluation of SRAT Sampling Data (U),” HLW/DWPF/TTR2005-0006, Revision 1, May 2, 2005.

[2] Edwards, TB, “Task Technical and Quality Assurance Plan: Evaluation of SRAT Sampling Data (U),” WSRC-RP-2005-01453, May 2, 2005.

[3] SAS Institute, Inc., JMP Statistics and Graphics Guide, SAS Institute, Inc., Cary, NC, 2002.

[4] Hsu, CW, "Defense Waste Processing Facility Nitric Acid Requirement for Treating Sludge (U),” WSRC-RP-92-1056, 1992.

[5] Jantzen, CM, JR Zamecnik, DC Koopman, CC Herman, and JB Pickett, "Electron Equivalents Model for Controlling Reduction-Oxidation (REDOX) Equilibrium During High Level Waste (HLW) Vitrification (U),”WSRC-TR-2003-00126, Revision 0, 2003.

[6] Coleman, HW and WG Steele, Experimentation and Uncertainty Analysis for Engineers, John Wiley \& Sons, Inc., New York, 1989.

[7] Edwards, TB and JR Harbour, "Sensitivity of Acid Addition Strategy to Input Uncertainties at DWPF for SB3,” SRT-SCS-2003-00027, June 19, 2003. 


\subsection{ACKNOWLEDGEMENTS}

The author would like to thank the members of the Yellow Belt Team (Joe Chen, Janice Cook, Bob Hoeppel, Roger Mahannah, Pete Patel, and Pam Woodward at DWPF and Connie Herman and Sharon Marra at SRNL) for their insights and guidance during this task. Special thanks to Connie (for her technical review of the activities associated with this task) and Joe (for his diligence in providing the data that served as the basis for the analyses presented in this report). 
WSRC-TR-2005-00292

Revision 0

APPENDIX

Supporting Tables and Exhibits 
WSRC-TR-2005-00292

Revision 0

This page intentionally left blank. 
WSRC-TR-2005-00292

Revision 0

Table A1. SRAT Receipt Measurements for Batches 314 through 323

\begin{tabular}{|c|c|c|c|c|c|c|c|c|c|c|}
\hline $\begin{array}{l}\text { SRAT Receipt } \\
\text { Batch }\end{array}$ & Sample & $\begin{array}{c}\text { Total Solids } \\
\text { (wt \%) }\end{array}$ & $\begin{array}{c}\text { Vol Density } \\
(\mathrm{g} / \mathrm{mL})\end{array}$ & $\begin{array}{c}\text { Total } \\
\text { Hydroxide } \\
\text { (eq/L) }\end{array}$ & $\begin{array}{c}\text { Formate } \\
\text { (ppm) }\end{array}$ & $\begin{array}{c}\text { Nitrate } \\
(\mathrm{ppm})\end{array}$ & $\begin{array}{l}\text { Nitrite } \\
(\mathrm{ppm})\end{array}$ & $\begin{array}{c}\text { Sulfate } \\
\text { (ppm) }\end{array}$ & $\begin{array}{c}\text { Oxalate } \\
(\text { ppm) }\end{array}$ & $\begin{array}{c}\text { TIC } \\
\text { (ppm) }\end{array}$ \\
\hline 314 & 1 & 18.62 & 1.117 & 0.183 & 6750 & 10600 & 11200 & 1600 & 992 & 946.5 \\
\hline 314 & 2 & 17.55 & 1.127 & 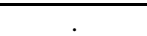 & 6750 & 10500 & 11000 & 1560 & 1010 & 890.9 \\
\hline 314 & 3 & 17.53 & 1.117 & . & 6780 & 10300 & 10900 & 1560 & 997 & 888.3 \\
\hline 314 & 4 & 17.47 & 1.123 & . & 6770 & 10400 & 10900 & 1560 & 1010 & 894.3 \\
\hline 314 & 5 & 17.74 & & & & & & & &. \\
\hline 315 & 1 & 18.83 & 1.15 & 0.187 & 8280 & 14000 & 13000 & 1890 & 1200 & 1021.8 \\
\hline 315 & 2 & 19.31 & 1.152 & . & 8190 & 12500 & 13100 & 1910 & 1190 & 959.8 \\
\hline 315 & 3 & 19.82 & 1.144 & . & 8220 & 12100 & 12800 & 1850 & 1190 & 962.9 \\
\hline 315 & 4 & 19.15 & 1.151 & . & 8230 & 12300 & 13000 & 1870 & 1200 & 913.4 \\
\hline 315 & 5 & 20.06 & . & . & . & . & . & . & . & . \\
\hline 315 & 6 & 20.12 & & & & & & & & . \\
\hline 316 & 1 & 17.33 & 1.121 & 0.193 & 8040 & 11700 & 11800 & 1760 & 1120 & 937.5 \\
\hline 316 & 2 & 18.26 & 1.126 &. & 8090 & 11800 & 11800 & 1760 & 1120 & 901.5 \\
\hline 316 & 3 & 18.08 & 1.129 & . & 7760 & 11400 & 11200 & 1680 & 1060 & 955.9 \\
\hline 316 & 4 & 18.72 & 1.128 & . & 7690 & 11200 & 11300 & 1680 & 1070 & 900.5 \\
\hline 316 & 5 & 18.37 &. & . &. &. &. &. &. &. \\
\hline 316 & 6 & 18.18 & & & & & & & & \\
\hline 317 & 1 & 18.86 & 1.16 & 0.191 & 8070 & 11400 & 11500 & 1730 & 1090 & 1011.6 \\
\hline 317 & 2 & 18.7 & 1.154 & & 8150 & 11200 & 11300 & 1730 & 1100 & 947.7 \\
\hline 317 & 3 & 18.09 & 1.144 & & 8090 & 11300 & 11400 & 1730 & 1100 & 1016.2 \\
\hline 317 & 4 & 19.29 & 1.151 & . & 8160 & 11300 & 11400 & 1710 & 1090 & 991.9 \\
\hline 317 & 5 & 18.77 & & & & & & & & \\
\hline 318 & 1 & 18.5 & 1.132 & 0.177 & 8890 & 12000 & 10500 & 1630 & 1040 & 945.1 \\
\hline 318 & 2 & 18.21 & 1.132 & & 8890 & 11700 & 10300 & 1630 & 1040 & 893.4 \\
\hline 318 & 3 & 18.26 & 1.163 & . & 8850 & 11700 & 10500 & 1630 & 1040 & 877.2 \\
\hline 318 & 4 & 18.13 & 1.176 & & 8940 & 11700 & 10300 & 1640 & 1040 & 859.3 \\
\hline 318 & 5 & 18.26 &. & . &. &. &. &. &. &. \\
\hline 318 & 6 & 18.36 & & & & & & & &. \\
\hline 319 & 1 & $\begin{array}{l}18.21 \\
\end{array}$ & 1.134 & 0.184 & 7420 & 10600 & 10900 & 1580 & 1000 & 965.8 \\
\hline 319 & 2 & 17.91 & 1.138 & 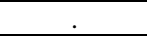 & 7320 & 10200 & 10600 & 1570 & 990 & 865.8 \\
\hline 319 & 3 & 18.31 & 1.135 & . & 7340 & 10400 & 10800 & 1580 & 1000 & 847.6 \\
\hline 319 & 4 & 18.23 & 1.169 & . & 7230 & 10100 & 10500 & 1550 & 989 & 856.9 \\
\hline 319 & 5 & 17.99 & . & . &. &. & . & . & . & . \\
\hline 319 & 6 & 18.63 & & & & & & & & . \\
\hline 320 & 1 & 16.53 & 1.155 & 0.174 & 8000 & 11700 & 11200 & 1540 & 977 & 938.1 \\
\hline 320 & 2 & 17.25 & 1.141 & . & 8050 & 11500 & 10400 & 1550 & 973 & 919.6 \\
\hline 320 & 3 & 16.32 & 1.142 &. & 8010 & 10400 & 9980 & 1550 & 990 & 889.7 \\
\hline 320 & 4 & 17.12 & 1.144 & . & 7960 & 10400 & 10000 & 1530 & 992 & 864.2 \\
\hline 320 & 5 & 17.26 & & & & & & & & \\
\hline 321 & 1 & 16.59 & 1.141 & 0.17 & 7540 & 10100 & 9780 & 1460 & 908 & 848.1 \\
\hline 321 & 2 & 16.25 & 1.135 & & 7460 & 10000 & 9650 & 1460 & 911 & 823.9 \\
\hline
\end{tabular}


WSRC-TR-2005-00292

Revision 0

Table A1. SRAT Receipt Measurements for Batches 314 through 323

\begin{tabular}{|c|c|c|c|c|c|c|c|c|c|c|}
\hline $\begin{array}{l}\text { SRAT Receipt } \\
\text { Batch } \\
\end{array}$ & Sample & $\begin{array}{c}\text { Total Solids } \\
\text { (wt\%) }\end{array}$ & $\begin{array}{c}\text { Vol Density } \\
\text { (g/mL) }\end{array}$ & $\begin{array}{c}\text { Total } \\
\text { Hydroxide } \\
\text { (eq/L) }\end{array}$ & $\begin{array}{c}\text { Formate } \\
\text { (ppm) }\end{array}$ & $\begin{array}{c}\text { Nitrate } \\
(\mathrm{ppm})\end{array}$ & $\begin{array}{r}\text { Nitrite } \\
(\mathrm{ppm})\end{array}$ & $\begin{array}{c}\text { Sulfate } \\
(\mathrm{ppm})\end{array}$ & $\begin{array}{c}\text { Oxalate } \\
(\mathrm{ppm})\end{array}$ & $\begin{array}{c}\text { TIC } \\
(\mathbf{p p m})\end{array}$ \\
\hline 321 & 3 & 16.2 & 1.193 & & 7380 & 9870 & 9730 & 1440 & 906 & 841.1 \\
\hline 321 & 4 & 16.54 & 1.183 & . & 7450 & 9980 & 9740 & 1450 & 907 & 824.8 \\
\hline 321 & 5 & 16.3 & $\dot{0}$ & . & $\cdot$ & . & . & . & . & . \\
\hline 321 & 6 & 16.19 & & & & & & & & . \\
\hline 322 & 1 & 18.97 & 1.12 & 0.16 & 7370 & 10300 & 10300 & 1550 & 957 & 846.7 \\
\hline 322 & 2 & 17.95 & 1.158 & & 7410 & 10200 & 10400 & 1560 & 959 & 789.8 \\
\hline 322 & 3 & 17.58 & 1.13 & & 7350 & 10400 & 10500 & 1570 & 956 & 816 \\
\hline 322 & 4 & 17.64 & 1.122 & & 7340 & 10300 & 10400 & 1530 & 944 & 819.2 \\
\hline 322 & 5 & 17.72 & & & 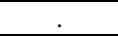 & 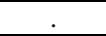 & 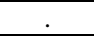 & 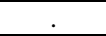 & . &. \\
\hline 322 & 6 & 17.84 & & & & & & &. &. \\
\hline 323 & 1 & 17.44 & 1.138 & 0.167 & 7140 & 9730 & 9650 & 1610 & 967 & 910.3 \\
\hline 323 & 2 & 17.53 & 1.154 &. & 7020 & 10700 & 11300 & 1600 & 953 & 864.5 \\
\hline 323 & 3 & 17.33 & 1.163 & . & 7110 & 10300 & 10900 & 1600 & 963 & 871.5 \\
\hline 323 & 4 & 17.77 & 1.137 & & 6410 & 10300 & 10800 & 1440 & 867 & 853 \\
\hline 323 & 5 & 17.76 & . & & $\cdot$ & $\cdot$ & . & . & . & . \\
\hline 323 & 6 & 17.83 & & & & . & . & . & . &. \\
\hline
\end{tabular}


Exhibit A1. Plots of the SRAT Receipt Measurements by Batch Number

SRAT Solids Mass (kg) By Batch

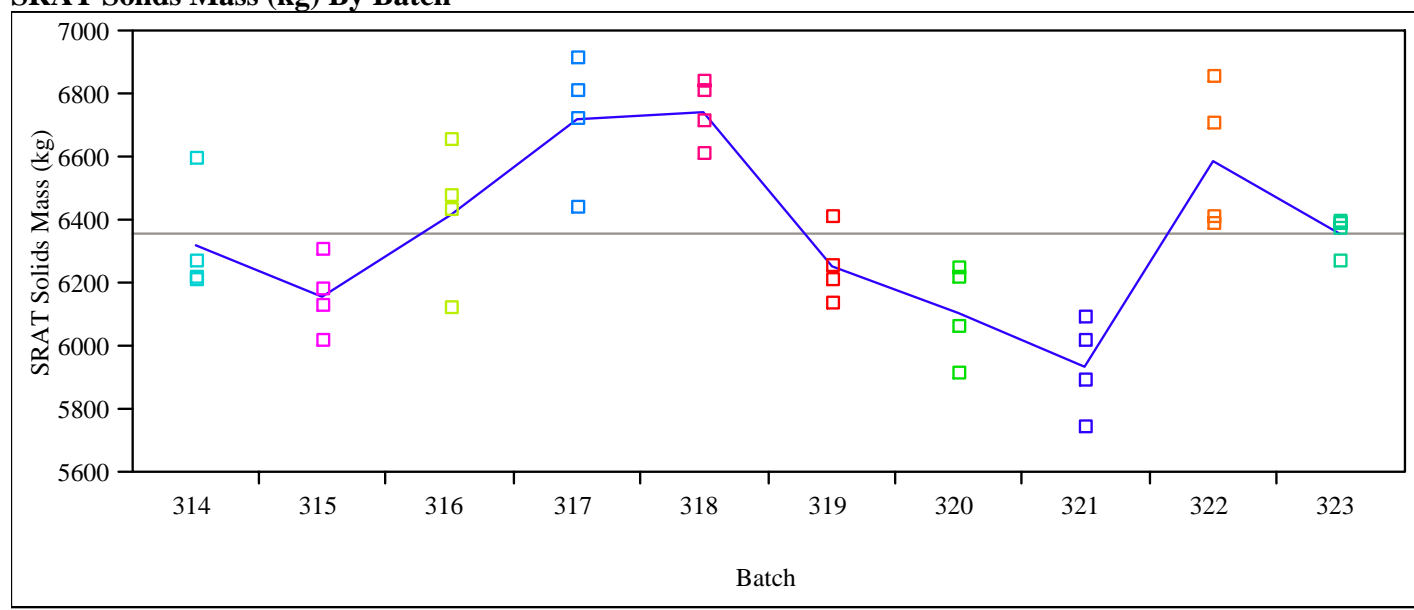

Missing Rows

17

Total Solids (wt\%) By Batch

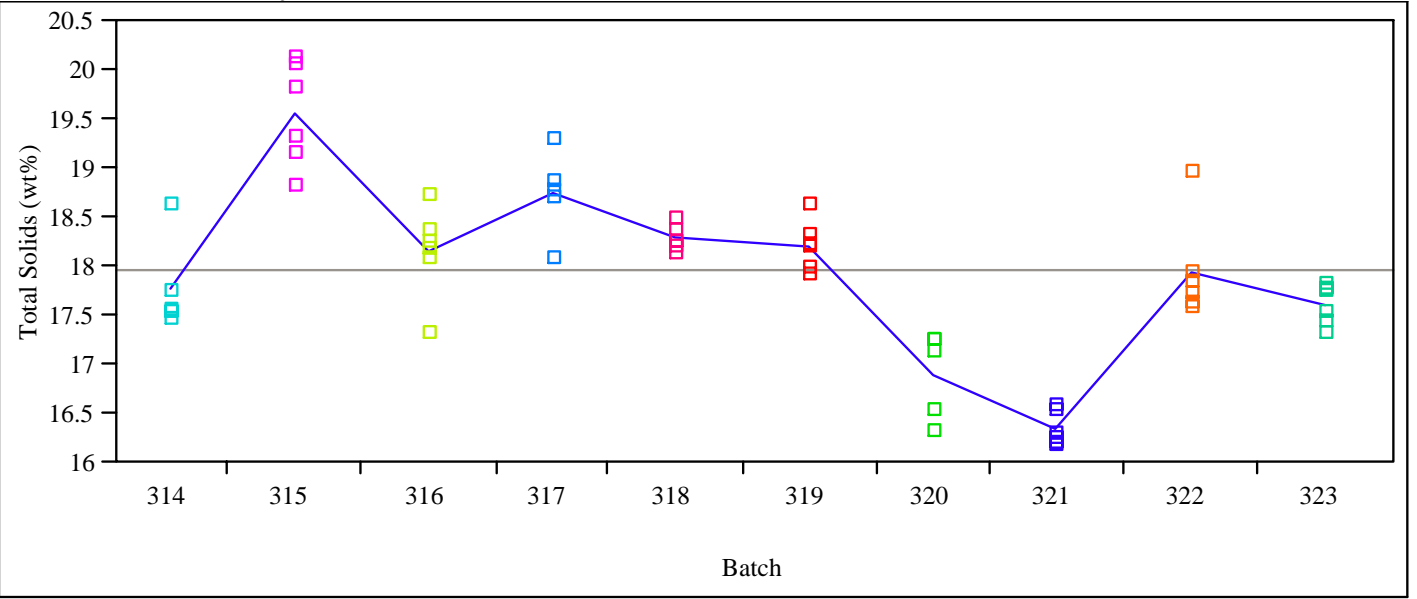

Vol Density (g/mL) By Batch

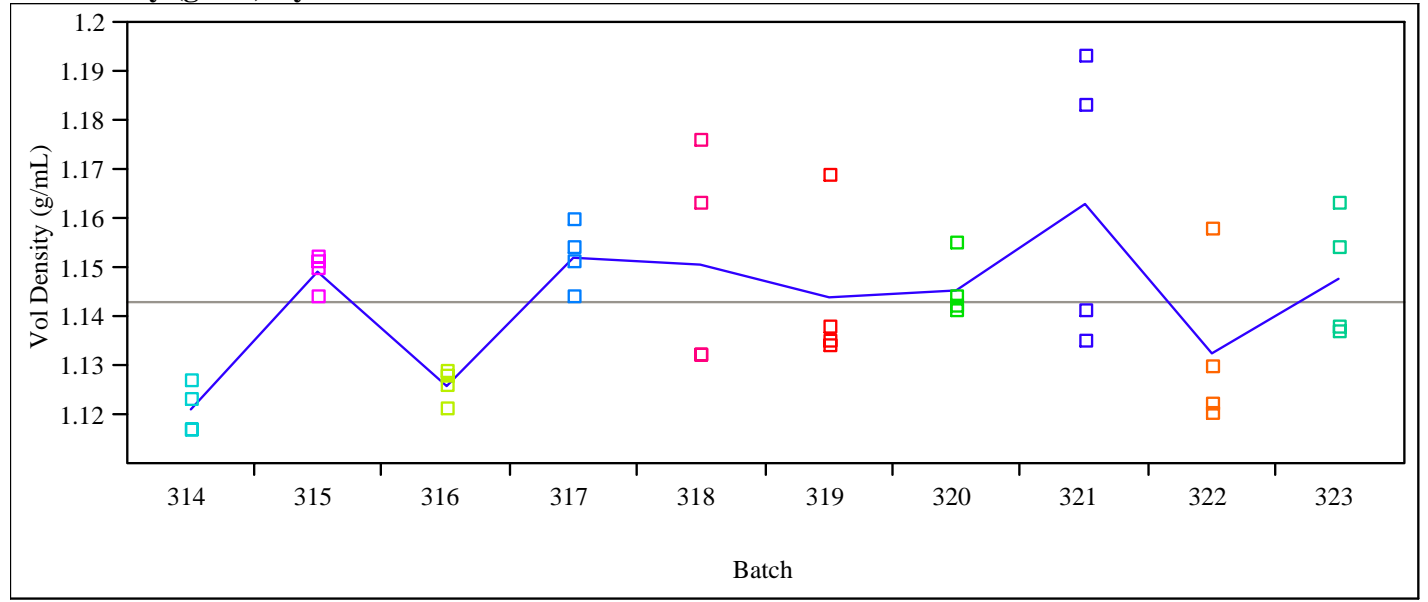

Missing Rows

17 
Exhibit A1. Plots of the SRAT Receipt Measurements by Batch Number

Total Hydroxide (eq/L) By Batch

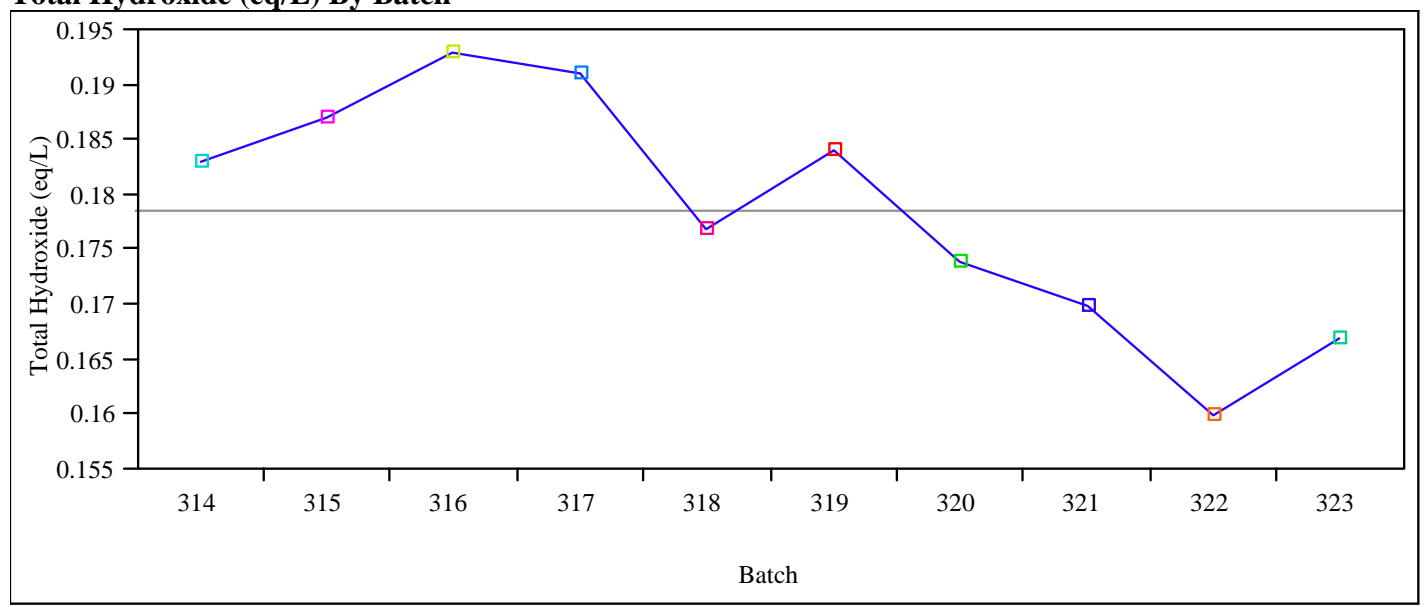

Missing Rows

47

Formate (ppm) By Batch

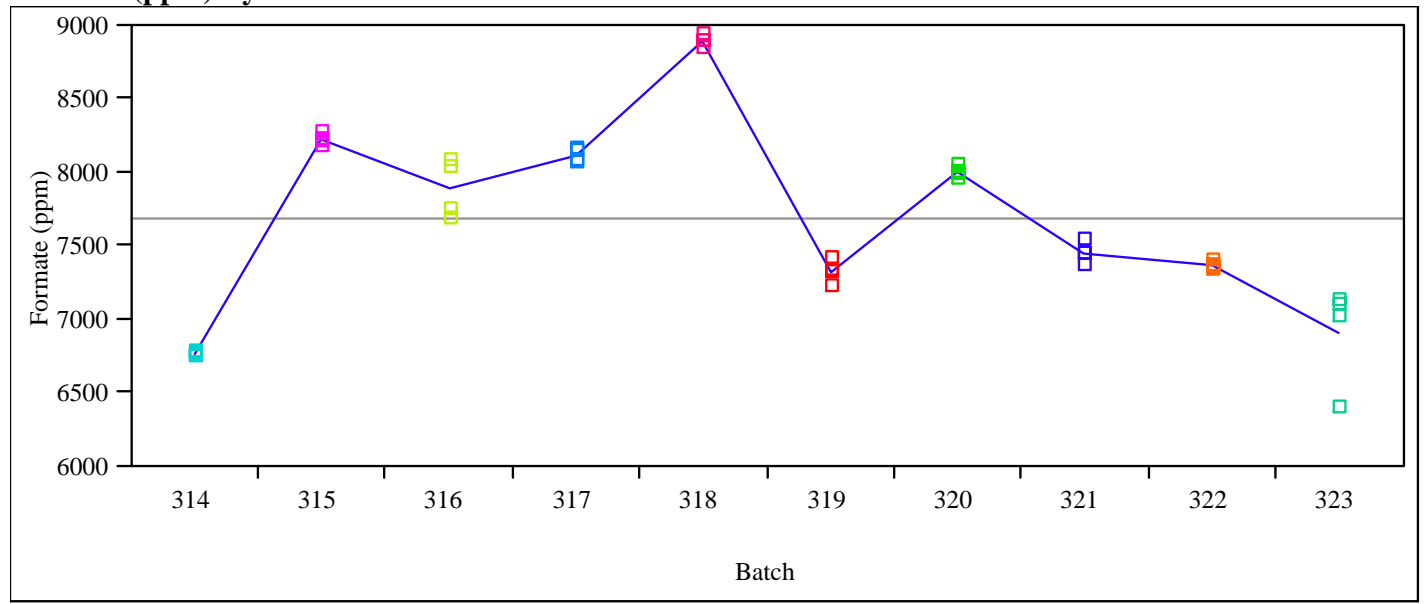

Missing Rows

17

Nitrate (ppm) By Batch

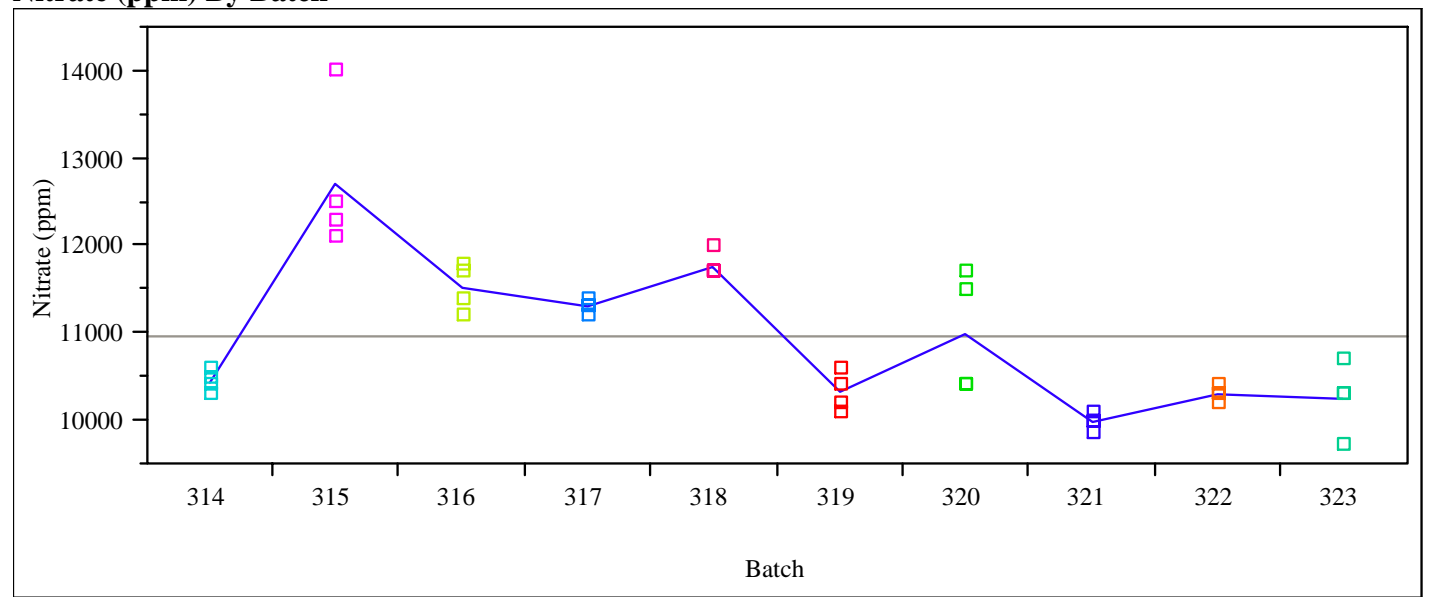

Missing Rows

17 
Exhibit A1. Plots of the SRAT Receipt Measurements by Batch Number

Nitrite (ppm) By Batch

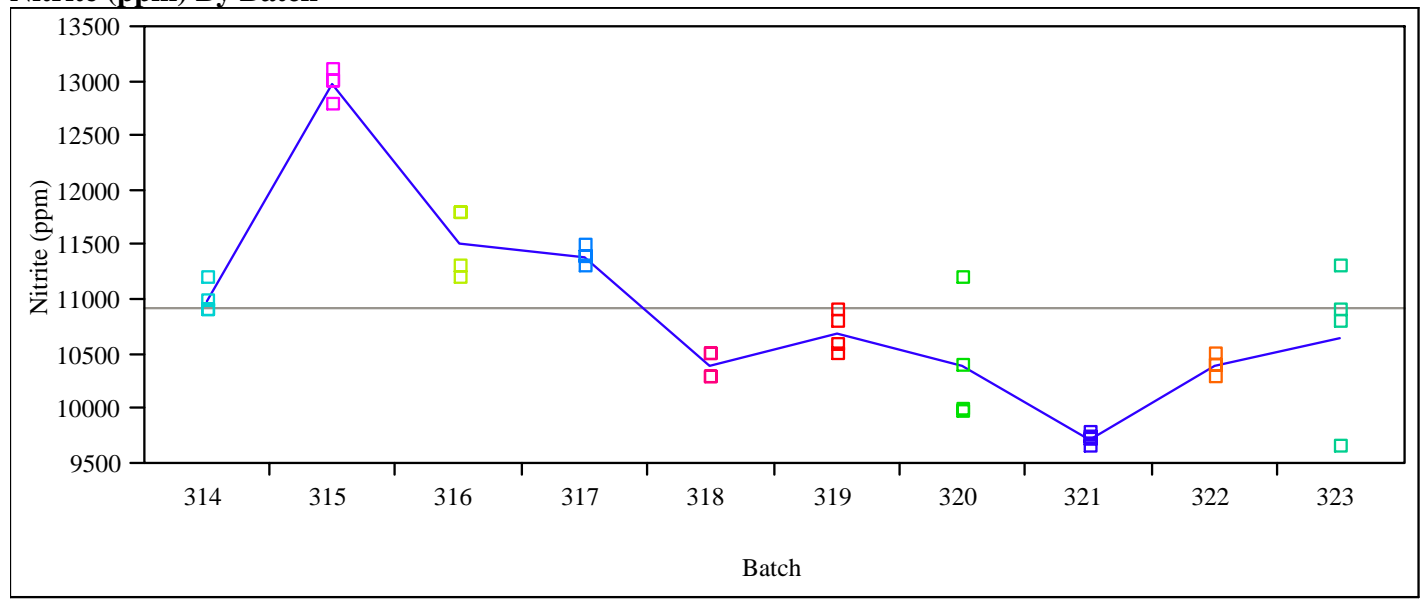

Missing Rows

17

Sulfate (ppm) By Batch

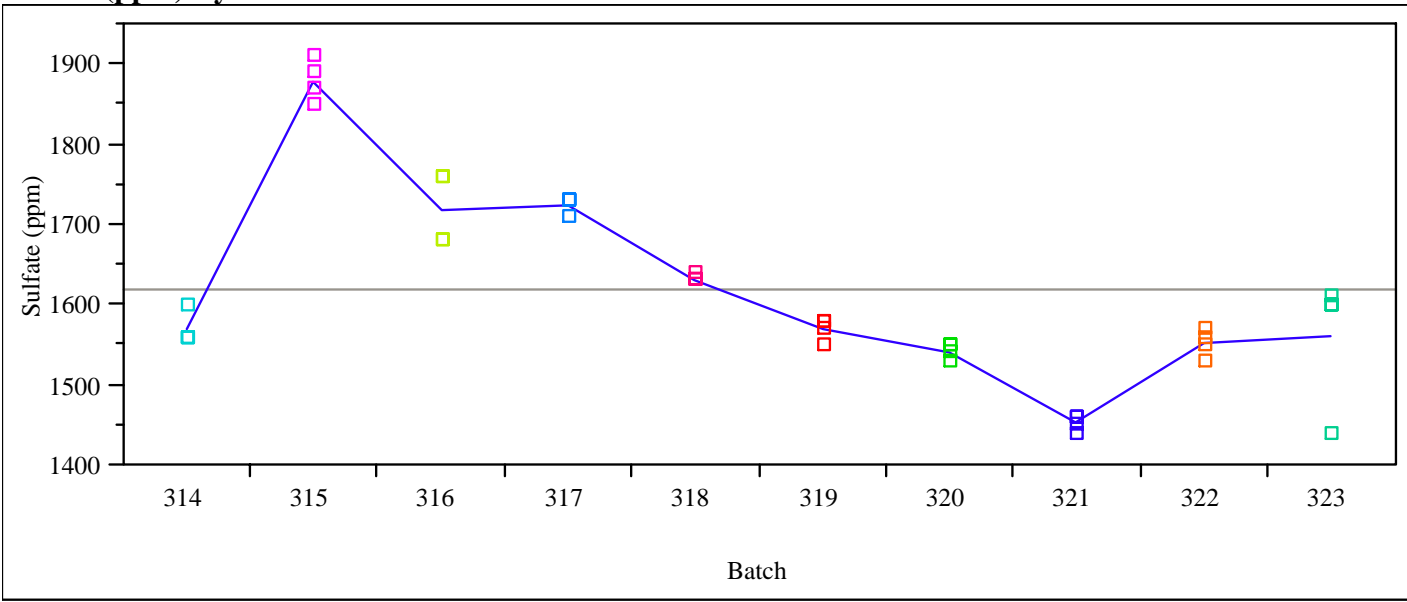

Missing Rows

17

Oxalate (ppm) By Batch

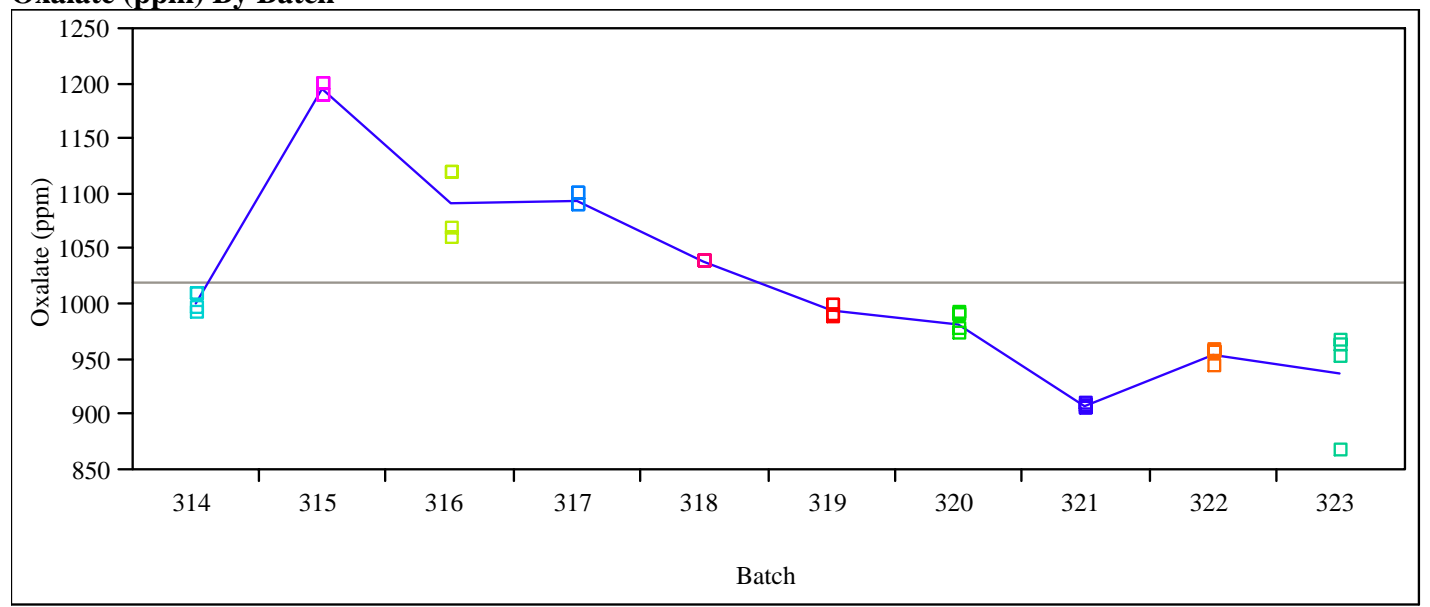

Missing Rows

17 
WSRC-TR-2005-00292

Revision 0

Exhibit A1. Plots of the SRAT Receipt Measurements by Batch Number

TIC (ppm) By Batch

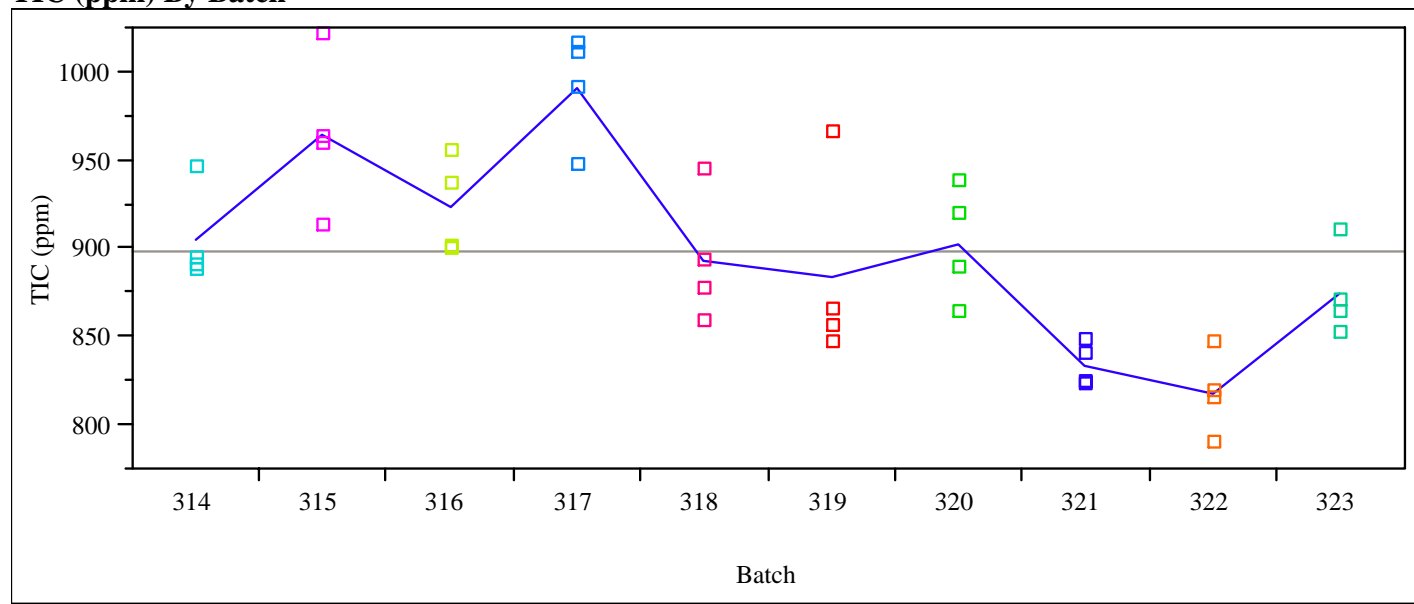

Missing Rows

17 
WSRC-TR-2005-00292

Revision 0

Exhibit A2. Plots SRAT Volumes, Nitric Acid Additions, and Formic Acid Additions by Batch Number

SRAT Volume (gal) By Batch

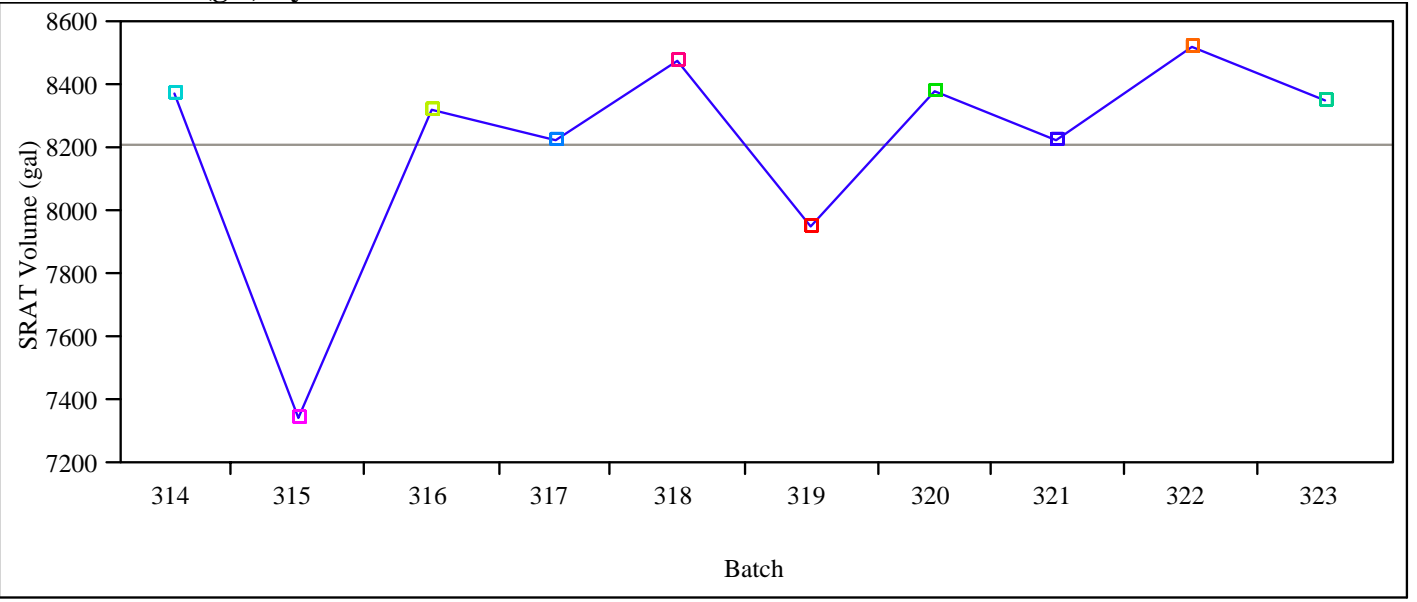

Nitric Acid (gal) By Batch

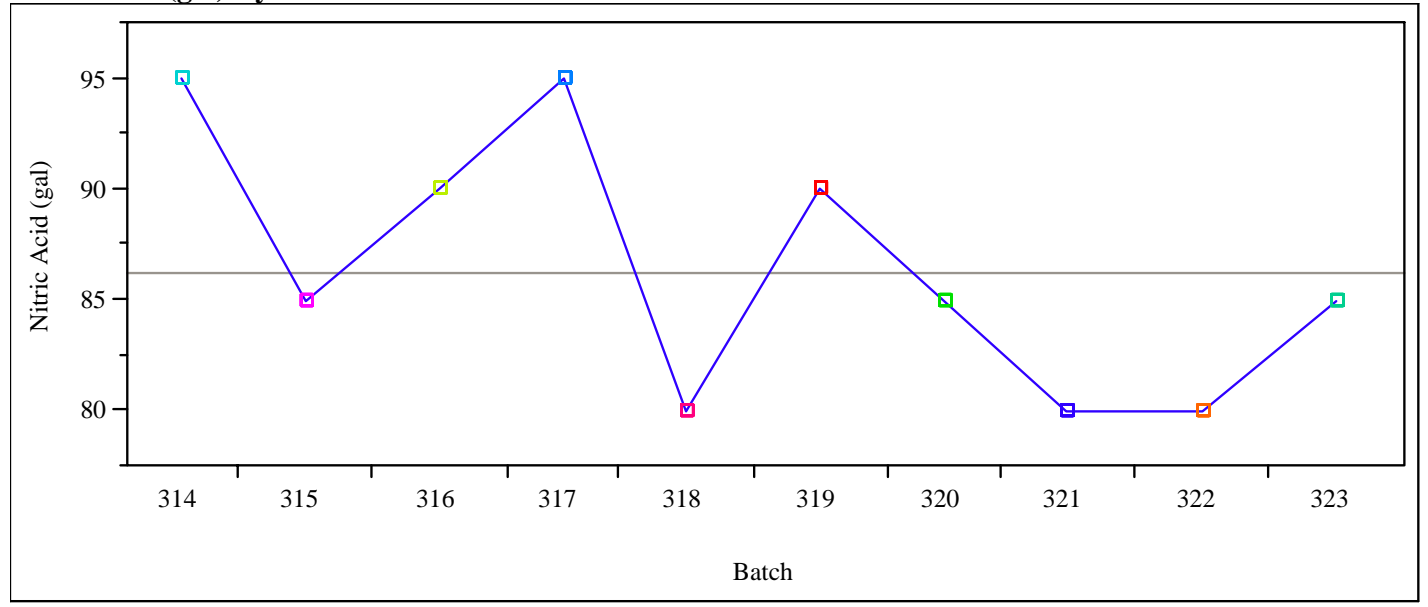

Formic Acid (gal) By Batch

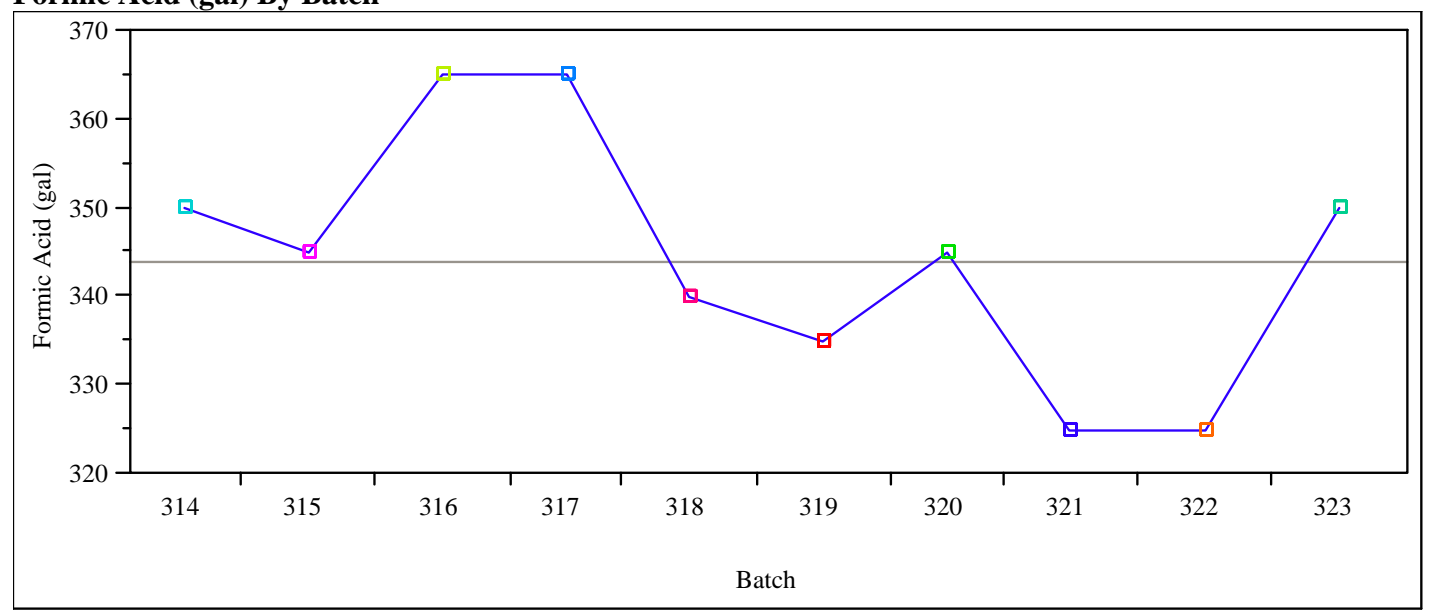




\section{Distribution:}

N.E. Bibler, 773-A

D.R. Best, 786-1A

T.B. Calloway, 999-W

J.N. Chen, 704-27S

J.E. Cook, 210-S

D.A. Crowley, 773-A

T.B. Edwards, 773-42A

M.T. Feller, 704-28S

T.L. Fellinger, 773-A

C.C. Herman, 773-42A

R.M. Hoeppel, 704-27S

E.W. Holtzscheiter, 773-A

C.M. Jantzen, 773-A

R.N. Mahannah, 704-28S

S.L. Marra, 999-W
W.L. Melton III, 704-28S

J.E. Occhipinti, 704-S

P.M. Patel, 704-27S

F.M. Pennebaker, 773-A

D.K. Peeler, 999-W

J.W. Ray, 704-S

E.P. Shine, 773-42A

J.A. Smith, 704-29S

M.E. Smith, 773-42A

T.K. Snyder, 999-W

M.E. Stone, 999-W

R.C. Tuckfield, 773-42A

J.P. Vaughan, 773-41A

F.A. Washburn, 704-28S

P.M. Woodward, 704-28S 